Research Article

\title{
2S2P1D Model Calibration Error from User Panel for One Bitumen and One Bituminous Mixture
}

\author{
S. Mangiafico $(\mathbb{D}$, C. Sauzéat, and H. Di Benedetto \\ Université de Lyon, École Nationale des Travaux Publics de l'État, LTDS (CNRS UMR 5513) Rue Maurice Audin, \\ 69518 Vaulx-en-Velin, France
}

Correspondence should be addressed to S. Mangiafico; salvatore.mangiafico@entpe.fr

Received 8 February 2019; Revised 4 April 2019; Accepted 18 April 2019; Published 26 May 2019

Guest Editor: Jose Norambuena-Contreras

Copyright ( 2019 S. Mangiafico et al. This is an open access article distributed under the Creative Commons Attribution License, which permits unrestricted use, distribution, and reproduction in any medium, provided the original work is properly cited.

The objective of this study is to analyse the differences between experimental LVE properties of both a straight-run bitumen and a bituminous mixture and simulations with analogical 2S2P1D (2 Springs, 2 Parabolic elements, and 1 Dashpot) model fitted by 14 different users. Data for the bitumen consisted of isotherms of $\left|G^{*}\right|$ and $\varphi$ obtained from DSR complex modulus tests at 12 different temperatures ranging from $-29.9^{\circ} \mathrm{C}$ to $60.0^{\circ} \mathrm{C}$ and frequencies ranging from 6.3 to $40 \mathrm{~Hz}$, for a total of 60 data points. Data for the bituminous mixture consisted of isotherms of $\left|E^{*}\right|$ and $\varphi$ obtained from strain-controlled traction/compression complex modulus tests at 8 different temperatures ranging from $-29.7^{\circ} \mathrm{C}$ to $38.8^{\circ} \mathrm{C}$ and frequencies ranging from 0.01 to $10 \mathrm{~Hz}$, for a total of 55 data points. All users worked independently and for the same time duration of one hour to fit the 2S2P1D model on both sets of data. Successful simulations of experimental data of both bitumen and mixture were generally obtained by all the users over the whole range of frequencies and temperatures, regardless of their familiarity and experience with the model. The accuracy of the model to fit experimental data is all the more evident if the great spans of complex modulus $\left(\left|G^{*}\right|\right.$ of the bitumen between $10^{-2}$ and $10^{3} \mathrm{MPa},\left|E^{*}\right|$ of the mixture between 10 and $40000 \mathrm{MPa}$ ) are considered. The obtained results highlight the convenience of 2S2P1D model to perform multiscale modelling of LVE behaviour of bituminous materials, from bitumens to mixtures.

\section{Introduction}

Modelling is an essential step in science. Several model-fitting methods, as well as sensitivity analysis methods, have been developed and are used in various scientific and engineering domains ([1-6], among others). The cited references offer a limited and nonexhaustive list of examples of existing methods, such as genetic algorithms, finite difference methods, direct differentiation methods, adjoint variable methods, etc.

In the domain of civil engineering, a wide range of models are available to simulate the various types of mechanical behaviour of construction materials. The 2S2P1D (2 Springs, 2 Parabolic creep elements, and 1 Dashpot) is a linear viscoelastic (LVE) analogical model developed at the University of Lyon/ENTPE to simulate the behaviour of all types of bituminous materials (bitumens, mastics, and bituminous mixtures) [7]. More details on the model are given in Section 2.

This model has gained attention in the scientific and technical community of the domain. The development of an accurate algorithm to automatically fit the model on a given set of experimental data by optimizing model constants is under way. Some studies are found in the literature where the model is calibrated by applying least square method to minimize the gap between experimental and simulated values of a specific LVE property (as an example, norm of complex modulus of binders was considered in [8]). However, its calibration is still generally performed manually by individual users. The model is fitted on experimental data by adapting the values of its constants through a trial and error procedure, until satisfactory simulations are obtained and visually judged [9].

To the extent of the knowledge of the authors, no study has been published yet on the variability of 2S2P1D simulations of the same materials obtained by different users.

The objective of this study was precisely to perform an analysis of the differences between experimental LVE properties of both a straight-run bitumen and a bituminous mixture (respectively, $G^{*}$ and $E^{*}$ ) and 2S2P1D simulations 
obtained by various users with different levels of expertise of the model.

\section{2S2P1D Analogical Model}

As indicated by the acronym, the analogical 2S2P1D model (Figure 1) is a partial derivative model consisting of an assembly of two linear elastic springs, two parabolic creep elements, and one Newtonian dashpot. For a given material with a LVE behaviour, the model can be used to simulate its complex modulus $E^{*}$ according to equation (1), where the variables are as follows: $\omega$ is the pulsation, related to frequency $f$ as $\omega=2 \pi f ; E_{00}$ is the asymptotic static modulus, for $\omega \longrightarrow 0 ; E_{0}$ is the asymptotic glassy modulus, for $\omega \longrightarrow \infty ; \delta$, $k$, and $h$ are dimensionless constants related to the two parabolic creep element, with $k<h ; \beta$ is a dimensionless constant related to the Newtonian dashpot as shown in equation (2); and $\tau$ is a characteristic time and the only constant of the model depending on temperature $\mathrm{T}$.

If the time-temperature superposition principle (TTSP) is respected, temperature shift factors $a_{\mathrm{T}}$ at any temperature T can be obtained as in equation (3), where $\tau_{0}$ is the value of $\tau$ at the reference temperature $T_{\text {ref }}$. Shift factors $a_{\mathrm{T}}$ can be fitted with the Williams-Landel-Ferry equation (4), as a function of constants $C_{1}$ and $C_{2}$ and reference temperature $T_{\text {reff }}$.

$$
\begin{aligned}
E^{*} & =E_{00}+\frac{E_{0}-E_{00}}{1+\delta(i \omega \tau)^{-k}+(i \omega \tau)^{-h}+(i \omega \beta \tau)^{-1}}, \\
\eta & =\left(E_{0}-E_{00}\right) \beta \tau, \\
a_{\mathrm{T}} & =\frac{\tau}{\tau_{0}}, \\
\log a_{\mathrm{T}} & =\frac{-C_{1}\left(T-T_{\mathrm{ref}}\right)}{C_{2}+T-T_{\text {ref }}} .
\end{aligned}
$$

The model can be used to simulate complex shear modulus $G^{*}$ of the same material, by replacing constants $E_{00}$ and $E_{0}$ with the corresponding constants $G_{00}$ and $G_{0}$ (Figure 1), respectively, equal to the static and glassy shear complex modulus, as in the following equation:

$$
G^{*}=G_{00}+\frac{G_{0}-G_{00}}{1+\delta(i \omega \tau)^{-k}+(i \omega \tau)^{-h}+(i \omega \beta \tau)^{-1}} .
$$

Complex modulus $E^{*}$ can be decomposed into its norm $\left(\left|E^{*}\right|\right)$ and phase angle $(\varphi)$, as well as its real $\left(E_{1}\right)$ and imaginary $\left(E_{2}\right)$ parts, as in equations $(6)$ and $(7)$. The same can be done for complex shear modulus $G^{*}$, as in equations (8) and (9).

$$
\begin{aligned}
E^{*} & =E_{1}+i E_{2}=\left|E^{*}\right| \cos \varphi+i\left|E^{*}\right| \sin \varphi=\left|E^{*}\right| e^{i \varphi}, \\
\left|E^{*}\right| & =\sqrt{E_{1}^{2}+E_{2}^{2}}, \\
\varphi & =\arctan \frac{E_{2}}{E_{1}}, \\
G^{*} & =G_{1}+i G_{2}=\left|G^{*}\right| \cos \varphi+i|G| \sin \varphi=\left|G^{*}\right| e^{i \varphi},
\end{aligned}
$$

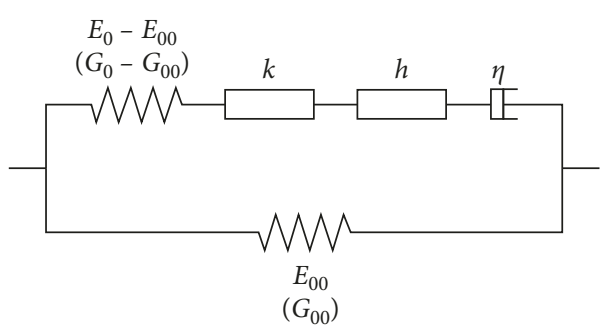

FIgUre 1: Analogical scheme of 2S2P1D model.

$$
\begin{aligned}
\left|G^{*}\right| & =\sqrt{G_{1}^{2}+G_{2}^{2}}, \\
\varphi & =\arctan \frac{G_{2}}{G_{1}} .
\end{aligned}
$$

In this paper, complex shear modulus $G^{*}$ was used to simulate the LVE behaviour of a bitumen, while complex modulus $E^{*}$ was used for a bituminous mixture. An extension of the model has been proposed to take into account the tridimensional linear viscoelastic behaviour of materials through their complex Poisson's ratio $[10,11]$. In this paper, only the unidimensional formulation of the model has been studied.

\section{Description of Input Experimental Data and Calibration Panel}

The LVE behaviour of a straight-run unaged bitumen and of a bituminous mixture was simulated using the 2S2P1D model. The model was fitted on experimental data available for these two materials.

Data for the bitumen consisted of isotherms of $\left|G^{*}\right|$ and $\varphi$ obtained from DSR complex modulus tests at 12 different temperatures ranging from $-29.90^{\circ} \mathrm{C}$ to $60.00^{\circ} \mathrm{C}$ and frequencies ranging from 6.3 to $40 \mathrm{~Hz}$, for a total of 60 data points (Figure 2). Data for the bituminous mixture consisted of isotherms of $\left|E^{*}\right|$ and $\varphi$ obtained from complex modulus tests (strain-controlled traction/compression sinusoidal loading on cylindrical specimens with a $75 \mathrm{~mm}$ diameter and $150 \mathrm{~mm}$ length) at 8 different temperatures ranging from $-29.65^{\circ} \mathrm{C}$ to $38.83^{\circ} \mathrm{C}$ and frequencies ranging from 0.01 to $10 \mathrm{~Hz}$, for a total of 55 data points (Figure 3).

Data for the two materials were given to a calibration panel, composed of 14 users (including master and $\mathrm{PhD}$ students, postdoctoral fellows, senior academic researchers, and professionals in private companies) with different levels of knowledge, familiarity, and experience of the 2S2P1D model, from beginners (having learnt the theory of the model and practicing with it for less than one week) to experienced users (with more than 10 years of knowledge and extensive practice of the model). All users were given one hour to perform the calibration of the model for both materials (bitumen and mixture). All users worked independently, without any communication with the other components of the panel.

Before fitting the 2S2P1D model on each material, every user had to shift the isotherms and obtain master curves of norm and phase angle of complex modulus $\left(G^{*}\right.$ and $E^{*}$ for 


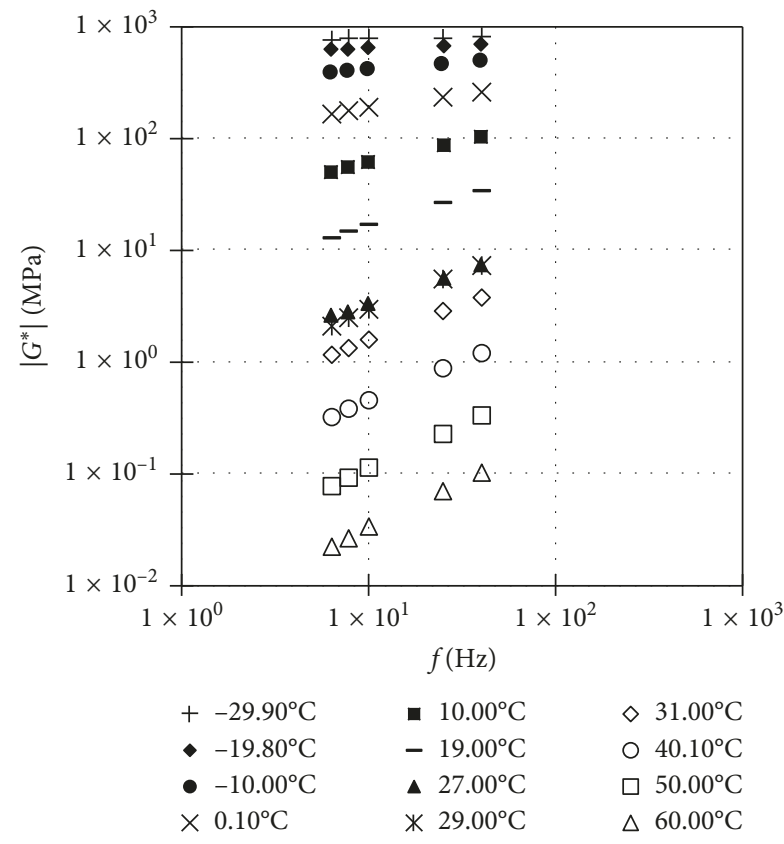

(a)

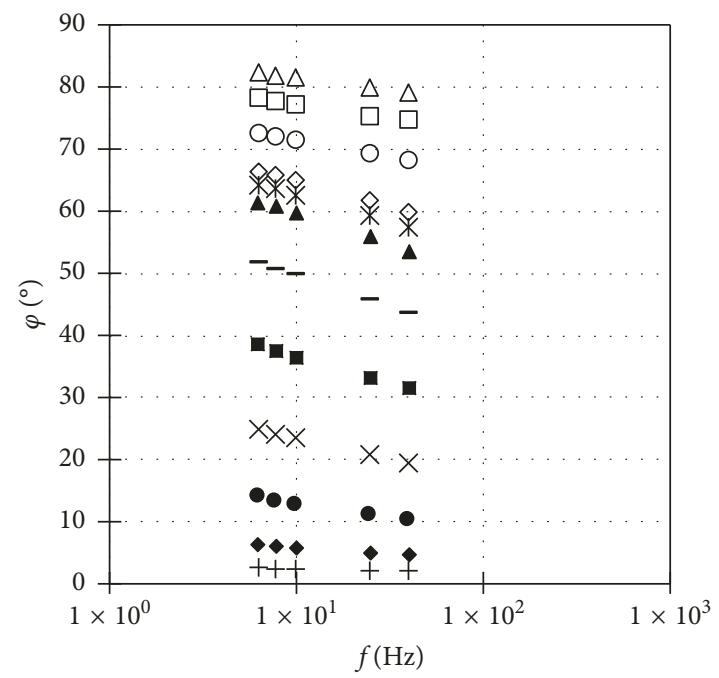

$$
\begin{aligned}
& \text { - }-19.80^{\circ} \mathrm{C} \\
& \text { - }-10.00^{\circ} \mathrm{C} \\
& \times 0.10^{\circ} \mathrm{C}
\end{aligned}
$$

(b)

Figure 2: Experimental data of the bitumen given to calibration panel: isotherms of norm (a) and phase angle (b) of complex shear modulus $G^{*}$.

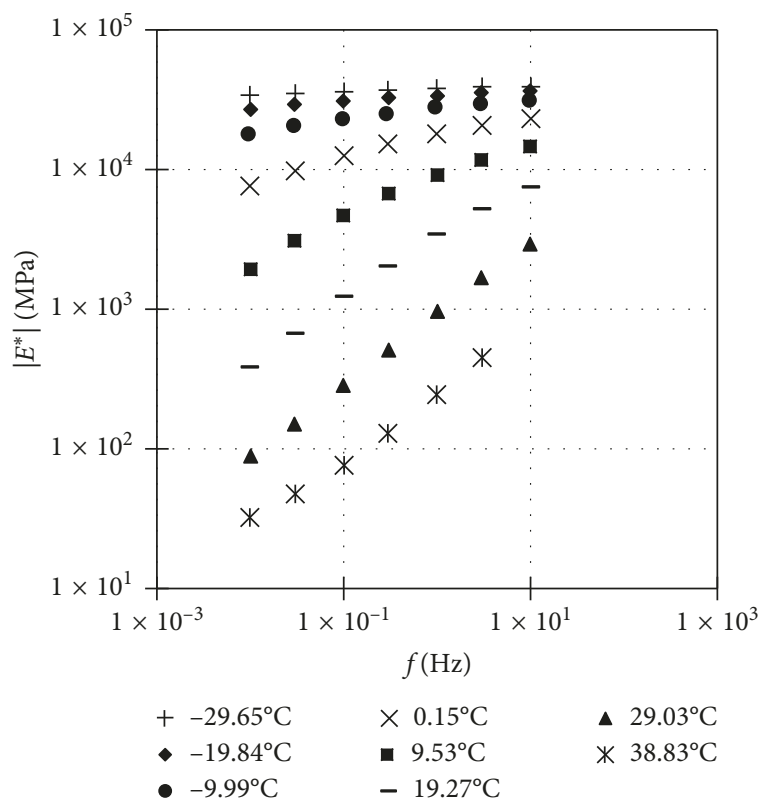

(a)

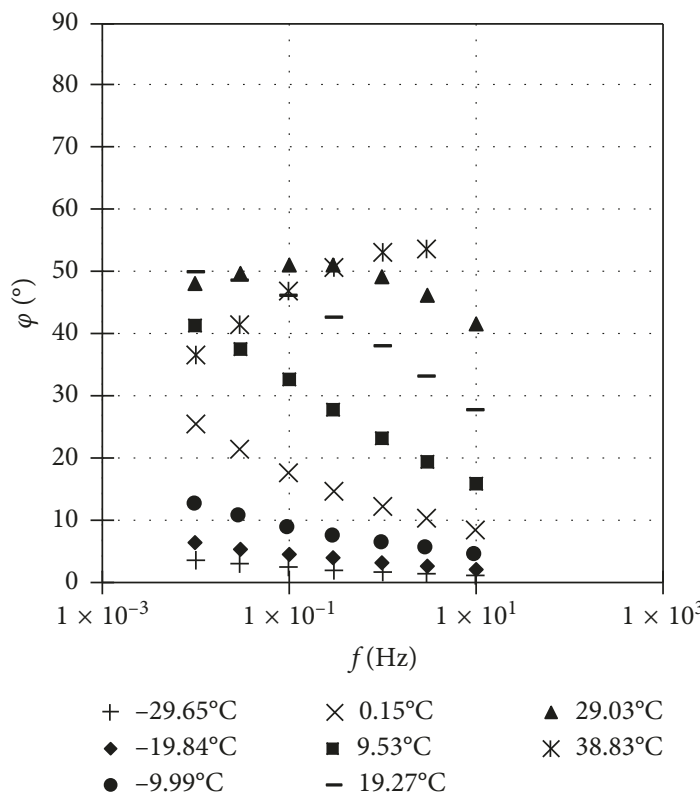

(b)

Figure 3: Experimental data of the bituminous mixture given to calibration panel: isotherms of norm (a) and phase angle (b) of complex modulus $E^{*}$.

the bitumen and the mixture, respectively). The reference temperatures of $10.00^{\circ} \mathrm{C}$ for the bitumen and $9.53^{\circ} \mathrm{C}$ for the mixture were imposed. For each $i$-th user, values of temperature shift factors $a_{\mathrm{T}_{i}}$ at all temperatures were first obtained by manually shifting isotherms and visually evaluating the goodness of the overlap. The WLF equation was then fitted on all values of $a_{\mathrm{T}_{i}}$ obtained for each material, therefore obtaining the values of $C_{1}$ and $C_{2}$ at the imposed reference temperature. For this reason, for the same material, every user obtained a different set of WLF constants and, therefore, slightly different master curves. The fitting of the 2S2P1D was performed on master curves 
obtained using shift factors calculated with the WLF equation.

At the end of the imposed time (one hour), each user was asked to give his/her values of the seven 2S2P1D constants $\left(G_{00}\right.$ or $E_{00}, G_{0}$ or $E_{0}, \delta, k, h, \beta$, and $\tau$ ) and the two WLF constants $\left(C_{1}\right.$ and $C_{2} ; T_{\text {ref }}$ was imposed $)$ for each material.

The same Microsoft Excel $^{\circledR}$ workbook, specifically designed to perform the fit, was given to all users. Several spreadsheets allow users to input data and compare experimental data points and simulated curves (WLF equation, Cole-Cole, Black and master curves).

\section{Analysis of Results from 2S2P1D Calibration Panel}

In this section, experimental data points and 2S2P1D simulations of all users are compared, for both materials. A quantitative estimation of the relative (for $\left|G^{*}\right|$ and $\left|E^{*}\right|$ ) and absolute (for $\varphi$ ) differences between data points and simulations is performed.

4.1. 2S2P1D Fitting for a Bitumen. Table 1 reports values of WLF and 2S2P1D constants obtained by all users of the calibration panel for the bitumen. Figure 4 shows a comparison of the simulations of the LVE behaviour of the bitumen obtained by all the users and the experimental data points. In particular, Figures 4(a) and 4(b) show, respectively, Black and Cole-Cole spaces, Figures 4(c) and 4(d) show master curves of, respectively, $\left|G^{*}\right|$ and $\varphi$, and Figure 4(e) shows the various WLF curves obtained by the users, together with the average WLF curve, according to the constants shown in Table 1. Experimental points shown in master curves of Figures 4(c) and 4(d) are shifted using shift factors calculated with the mentioned average WLF curve, with the only purpose of having a graphical representation.

Apart from $G_{00}$, imposed equal to zero by all user, the constant with the lowest coefficient of variation (COV, defined as the ratio between standard deviation and mean) is $G_{0}(1.62 \%)$, followed by the two constants $k$ and $h$ associated with the parabolic elements (lower than 7\%). Although a high COV is observed for the characteristic time $\tau$, the variability of this constant is more rigorously evaluated by considering its logarithm $\log \tau$ (whose COV is lower than $6 \%$ in absolute value), as it can be easily understood by taking into account its relationship with temperature and viscosity (equations (2) and (3)).

Generally satisfactory approximations of experimental points are obtained with 2S2P1D simulations of all users. At low frequency/high temperature, slight underestimation of $\left|G^{*}\right|$ and overestimation of $\varphi$ are observed for all users. However, these differences between the model and the experimental points are negligible in absolute value (less than $100 \mathrm{kPa}$ for $\left.\left|G^{*}\right|\right)$.

In order to have a quantitative estimation of the differences between the 2S2P1D simulation obtained by each $i$-th user and experimental points, relative errors $\delta_{G_{1}}, \delta_{G_{2}}$ and $\delta_{\left|G^{*}\right|_{i}}$ (respectively for $G_{1}, G_{2}$ and $\left|G^{*}\right|$ ) and absolute error $\delta_{\varphi_{i}}$ (for $\varphi$ ) were calculated for each equivalent frequency $a_{\mathrm{T}_{i}} \omega$ (60 data points) according to the following equations:

$$
\begin{aligned}
& \delta_{G_{1_{i}}}\left(a_{\mathrm{T}_{i}} \omega\right)=\frac{G_{1, \exp }\left(a_{\mathrm{T}_{i}} \omega\right)-G_{1,2 \mathrm{~S} 2 \mathrm{P} 1 \mathrm{D}_{i}}\left(a_{\mathrm{T}_{i}} \omega\right)}{G_{1, \exp }\left(a_{\mathrm{T}_{i}} \omega\right)}, \\
& \delta_{G_{2_{i}}}\left(a_{\mathrm{T}_{i}} \omega\right)=\frac{G_{2, \exp }\left(a_{\mathrm{T}_{i}} \omega\right)-G_{2,2 \mathrm{~S}_{\mathrm{P}} 1 \mathrm{D}_{i}}\left(a_{\mathrm{T}_{i}} \omega\right)}{G_{2, \exp }\left(a_{\mathrm{T}_{i}} \omega\right)}, \\
& \delta_{\left|G^{*}\right|_{i}}\left(a_{\mathrm{T}_{i}} \omega\right)=\frac{\left|G_{\mathrm{exp}}^{*}\right|\left(a_{\mathrm{T}_{i}} \omega\right)-\left|G_{2 \mathrm{~S} 2 \mathrm{P} 1 \mathrm{D}_{i}}^{*}\right|\left(a_{\mathrm{T}_{i}} \omega\right)}{\left|G_{\exp }^{*}\right|\left(a_{\mathrm{T}_{i}} \omega\right)}, \\
& \delta_{\varphi_{i}}\left(a_{\mathrm{T}_{i}} \omega\right)=\varphi_{\exp }\left(a_{\mathrm{T}_{i}} \omega\right)-\varphi_{2 \mathrm{~S}_{\mathrm{P} 1 \mathrm{D}_{i}}}\left(a_{\mathrm{T}_{i}} \omega\right),
\end{aligned}
$$

where $\quad G_{1, \exp }\left(a_{\mathrm{T}_{i}} \omega\right), \quad G_{2, \exp }\left(a_{\mathrm{T}_{i}} \omega\right), \quad\left|G_{\exp }^{*}\right|\left(a_{\mathrm{T}_{i}} \omega\right), \quad$ and $\varphi_{\exp }\left(a_{\mathrm{T}_{i}} \omega\right)$ are experimental values of, respectively, $G_{1}, G_{2}$, $\left|G^{*}\right|$, and $\varphi$ at the equivalent frequency $a_{\mathrm{T}_{i}} \omega \cdot G_{1,2 \mathrm{~S}_{2} \mathrm{P}_{1} \mathrm{D}_{i}}\left(a_{\mathrm{T}_{i}} \omega\right)$, $G_{2,2 \mathrm{~S} 2 \mathrm{P} 1 \mathrm{D}_{i}}\left(a_{\mathrm{T}_{i}} \omega\right), \quad\left|G_{2 \mathrm{~S} 2 \mathrm{P} 1 \mathrm{D}_{i}}^{*}\right|\left(a_{\mathrm{T}_{i}} \omega\right)$, and $\varphi_{2 \mathrm{~S}_{2} \mathrm{P}_{1} \mathrm{D}_{i}}\left(a_{\mathrm{T}_{i}} \omega\right)$ are values of, respectively, $G_{1}, G_{2},\left|G^{*}\right|$, and $\varphi$ at the equivalent frequency $a_{\mathrm{T}_{i}} \omega$, calculated with the 2S2P1D according to the constants of the $i$-th user reported in Table 1.

Master curves of $\delta_{G_{1_{i}}}, \delta_{G_{2 i}}, \delta_{\left|G^{*}\right|_{i}}$, and $\delta_{\varphi_{i}}$ are shown in Figure 5. Bold lines represent $10 \%$ and $5^{\circ}$ limits for, respectively, relative and absolute errors. In order to avoid confusion, it is very important to highlight that errors $\delta_{G_{1}}, \delta_{G_{2_{i}}}, \delta_{\left|G^{*}\right|_{i}}$, and $\delta_{\varphi_{i}}$ were calculated for each $i$-th user at equivalent frequencies obtained with shift factors $a_{\mathrm{T}_{i}}$ calculated according to his/her WLF constants shown in Table 1. For this reason, the total range of equivalent frequencies is slightly different for each user. The results confirm the qualitative judgement made from Figure 4. The relative errors observed for equivalent frequencies lower than approximately $10^{1} \mathrm{~Hz}$ are negligible because of the low values of $G_{1}, G_{2}$, and $\left|G^{*}\right|$ at these frequencies (lower than $100 \mathrm{kPa}$ ). The error for phase angle $\varphi$ is generally lower than $5^{\circ}$, apart from some exceptions for some users.

The accuracy of the model to fit experimental data is all the more evident if the great spans of equivalent frequencies (between $10^{-6}$ and $10^{10} \mathrm{~Hz}$ at the reference temperature of $10^{\circ} \mathrm{C}$ ) and $\left|G^{*}\right|$ (between $10^{-2}$ and $10^{3} \mathrm{MPa}$ ) are taken into consideration. The three most experienced users (2, 5, and 12) of the panel obtained particularly accurate approximations of experimental data, as shown by their corresponding master curves (at $10^{\circ} \mathrm{C}$ ) of relative errors for $\left|G^{*}\right|$ and absolute errors for $\varphi$ in Figure 6. This observation confirms the ability of the model to accurately simulate LVE behaviour of bitumens.

For each user, global error parameters over the whole range of frequencies were calculated for each of the considered relative and absolute errors. Equations (14)-(17) were used to calculate average values $\left(\overline{\delta_{G_{1}}}, \overline{\delta_{G_{2}}}, \overline{\delta_{\left|G^{*}\right|_{i}}}\right.$, and $\left.\overline{\delta_{\varphi_{i}}}\right)$ and standard deviations $\left(\mu_{G_{1_{i}}}, \mu_{G_{2_{i}}}, \mu_{\left|G^{*}\right|_{i}}\right.$, and $\left.\mu_{\varphi_{i}}\right)$ of relative and absolute errors of each user at the $N$ considered equivalent frequencies $a_{\mathrm{T}_{i}}(N=60)$, plotted in histograms of Figure 7. Error bars are plotted according to standard deviation values. 
TABLE 1: WLF and 2S2P1D constants obtained for the bitumen by all the users of the calibration panel $\left(T_{\text {ref }}=10.00^{\circ} \mathrm{C}\right)$.

\begin{tabular}{lcccccccccc}
\hline & $C_{1}(-)$ & $C_{2}\left({ }^{\circ} \mathrm{C}\right)$ & $G_{00}(\mathrm{MPa})$ & $G_{0}(\mathrm{MPa})$ & $\delta(-)$ & $k(-)$ & $h(-)$ & $\beta(-)$ & $\tau(\mathrm{s})$ & $\log \tau(-)$ \\
\hline User 1 & 22.98 & 165.49 & 0 & 877 & 2.38 & 0.223 & 0.560 & 115 & $4.10 \times 10^{-4}$ & -3.39 \\
User 2 & 16.89 & 120.95 & 0 & 900 & 1.90 & 0.195 & 0.500 & 200 & $1.50 \times 10^{-4}$ & -3.82 \\
User 3 & 22.56 & 169.33 & 0 & 900 & 1.79 & 0.195 & 0.510 & 250 & $1.90 \times 10^{-4}$ & -3.72 \\
User 4 & 24.16 & 178.59 & 0 & 888 & 1.95 & 0.205 & 0.515 & 230 & $2.00 \times 10^{-4}$ & -3.70 \\
User 5 & 19.05 & 141.39 & 0 & 900 & 2.10 & 0.204 & 0.550 & 200 & $2.70 \times 10^{-4}$ & -3.57 \\
User 6 & 18.30 & 137.00 & 0 & 870 & 2.60 & 0.230 & 0.600 & 100 & $5.50 \times 10^{-4}$ & -3.26 \\
User 7 & 28.83 & 200.18 & 0 & 880 & 2.30 & 0.217 & 0.560 & 140 & $3.00 \times 10^{-4}$ & -3.52 \\
User 8 & 30.86 & 196.09 & 0 & 900 & 2.20 & 0.210 & 0.550 & 200 & $3.40 \times 10^{-4}$ & -3.47 \\
User 9 & 32.31 & 235.19 & 0 & 900 & 1.88 & 0.200 & 0.500 & 300 & $1.80 \times 10^{-4}$ & -3.74 \\
User 10 & 32.17 & 223.30 & 0 & 893 & 2.00 & 0.204 & 0.550 & 220 & $2.50 \times 10^{-4}$ & -3.60 \\
User 11 & 18.03 & 124.75 & 0 & 862 & 2.70 & 0.235 & 0.608 & 80 & $6.00 \times 10^{-4}$ & -3.22 \\
User 12 & 25.37 & 179.43 & 0 & 870 & 2.53 & 0.226 & 0.580 & 115 & $4.80 \times 10^{-4}$ & -3.32 \\
User 13 & 23.15 & 170.33 & 0 & 870 & 2.60 & 0.230 & 0.580 & 120 & $5.00 \times 10^{-4}$ & -3.30 \\
User 14 & 26.05 & 203.21 & 0 & 900 & 1.85 & 0.197 & 0.505 & 400 & $2.00 \times 10^{-4}$ & -3.70 \\
\hline Mean & 24.34 & 174.66 & 0 & 886 & 2.20 & 0.212 & 0.548 & 191 & $3.30 \times 10^{-4}$ & -3.52 \\
St. dev. & 5.25 & 35.11 & 0 & 14 & 0.32 & 0.014 & 0.037 & 88 & $1.52 \times 10^{-4}$ & 0.20 \\
COV & $21.56 \%$ & $20.10 \%$ & - & $1.62 \%$ & $14.48 \%$ & $6.72 \%$ & $6.73 \%$ & $46.32 \%$ & $45.91 \%$ & $-5.68 \%$ \\
\hline
\end{tabular}

Note. Coefficient of variation (COV): standard deviation/mean.

$$
\begin{aligned}
& \overline{\delta_{G_{1_{i}}}}=\frac{\sum_{a_{\mathrm{T}_{i}} \omega} \delta_{G_{1_{i}}}\left(a_{\mathrm{T}_{i}} \omega\right)}{N}, \\
& \mu_{G_{1_{i}}}=\sqrt{\frac{\sum_{a_{\mathrm{T}_{i}} \omega}\left[\delta_{G_{1_{i}}}\left(a_{T_{i}} \omega\right)-\overline{\delta_{G_{1_{i}}}}\right]^{2}}{N}}, \\
& \overline{\delta_{G_{2_{i}}}}=\frac{\sum_{a_{\mathrm{T}_{i}} \omega} \delta_{G_{2_{i}}}\left(a_{\mathrm{T}_{i}} \omega\right)}{N}, \\
& \mu_{G_{2_{i}}}=\sqrt{\frac{\sum_{a_{\mathrm{T}_{i}} \omega}\left[\delta_{G_{2_{i}}}\left(a_{\mathrm{T}_{i}} \omega\right)-\overline{\delta_{G_{2_{i}}}}\right]^{2}}{N}},
\end{aligned}
$$

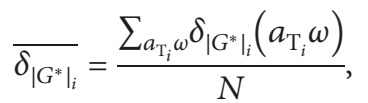

$$
\begin{aligned}
& \mu_{\left|G^{*}\right|_{i}}=\sqrt{\frac{\sum_{a_{\mathrm{T}_{i}} \omega}\left[\delta_{\left|G^{*}\right|_{i}}\left(a_{\mathrm{T}_{i}} \omega\right)-\overline{\delta_{\left|G^{*}\right|_{i}}}\right]^{2}}{N}}, \\
& \overline{\delta_{\varphi_{i}}}=\frac{\sum_{a_{\mathrm{T}_{i}} \omega} \delta_{\varphi_{i}}\left(a_{\mathrm{T}_{i}} \omega\right)}{N}, \\
& \mu_{\varphi_{i}}=\sqrt{\frac{\sum_{a_{\mathrm{T}_{i}} \omega}\left[\delta_{\varphi_{i}}\left(a_{\mathrm{T}_{i}} \omega\right)-\overline{\delta_{\varphi_{i}}}\right]^{2}}{N}} .
\end{aligned}
$$

A further error estimation was performed by considering absolute values of errors $\delta_{G_{1_{i}}}, \delta_{G_{2_{i}}}, \delta_{\left|G^{*}\right|_{i}}$, and $\delta_{\varphi_{i}}$. Therefore, equations (18)-(21) were used to calculate average values $\left(\overline{\Delta_{G_{1}}}, \overline{\Delta_{G_{2_{i}}}}, \overline{\Delta_{\left|G^{*}\right|_{i}}}\right.$, and $\left.\overline{\Delta_{\varphi_{i}}}\right)$ and standard deviations $\left(M_{G_{1_{i}}}\right.$, $M \mu_{G_{2_{i}}}, M \mu_{\left|G^{*}\right|_{i}}$, and $M_{\varphi_{i}}$ ) of absolute values of relative and absolute errors of each user at the $N$ considered equivalent frequencies $a_{\mathrm{T}_{i}}(N=60)$, plotted in histograms of Figure 8 . As in Figure 7, error bars are plotted according to standard deviation values.

$$
\begin{aligned}
& \overline{\Delta_{G_{1_{i}}}}=\frac{\sum_{a_{\mathrm{T}_{i}} \omega}\left|\delta_{G_{i}}\left(a_{\mathrm{T}_{i}} \omega\right)\right|}{N}, \\
& M_{G_{1_{i}}}=\sqrt{\frac{\sum_{a_{\mathrm{T}_{i}} \omega}\left[\left|\delta_{G_{1_{i}}}\left(a_{\mathrm{T}_{i}} \omega\right)\right|-\overline{\Delta_{G_{1_{i}}}}\right]^{2}}{N}}, \\
& \overline{\Delta_{G_{2_{i}}}}=\frac{\sum_{a_{\mathrm{T}_{i}} \omega}\left|\delta_{G_{2_{i}}}\left(a_{\mathrm{T}_{i}} \omega\right)\right|}{N} \\
& M_{G_{2_{i}}}=\sqrt{\frac{\sum_{a_{\mathrm{T}_{i}} \omega}\left[\left|\delta_{G_{2_{i}}}\left(a_{\mathrm{T}_{i}} \omega\right)\right|-\overline{\Delta_{G_{2_{i}}}}\right]^{2}}{N}}, \\
& \overline{\Delta_{\left|G^{*}\right|_{i}}}=\frac{\sum_{a_{\mathrm{T}_{i}} \omega}\left|\delta_{\left|G^{*}\right|_{i}}\left(a_{\mathrm{T}_{i}} \omega\right)\right|}{N}, \\
& M_{\left|G^{*}\right|_{i}}=\sqrt{\frac{\sum_{a_{\mathrm{T}_{i}} \omega}\left[\left|\delta_{\left|G^{*}\right|_{i}}\left(a_{\mathrm{T}_{i}} \omega\right)\right|-\overline{\Delta_{\left|G^{*}\right|_{i}}}\right]^{2}}{N}}, \\
& \overline{\Delta_{\varphi_{i}}}=\frac{\sum_{a_{\mathrm{T}_{i}} \omega}\left|\delta_{\varphi_{i}}\left(a_{\mathrm{T}_{i}} \omega\right)\right|}{N} \\
& M_{\varphi_{i}}=\sqrt{\frac{\sum_{a_{\mathrm{T}_{i}} \omega}\left[\left|\delta_{\varphi_{i}}\left(a_{\mathrm{T}_{i}} \omega\right)\right|-\overline{\Delta_{\varphi_{i}}}\right]^{2}}{N} .}
\end{aligned}
$$

Apart from some exceptions regarding few users, global error parameters for phase angle are generally lower than $5^{\circ}$ even considering the corresponding standard deviations. Higher error parameters are found for $G_{1}, G_{2}$, and $\left|G^{*}\right|$, especially when absolute values of errors are considered. However, these parameters were calculated by arithmetically averaging all the 60 data points over the whole frequency range available. For this reason, 

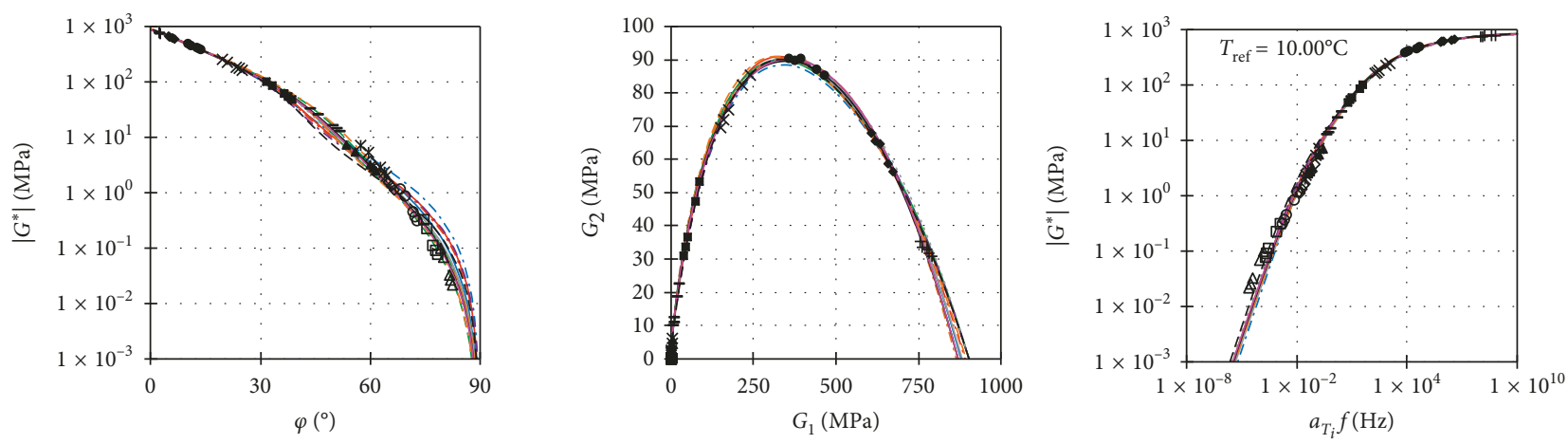

$\begin{array}{ll}+-29.90^{\circ} \mathrm{C} & \Delta 27.00^{\circ} \mathrm{C} \\ --19.80^{\circ} \mathrm{C} & \approx 29.00^{\circ} \mathrm{C} \\ --10.00^{\circ} \mathrm{C} & \diamond 31.00^{\circ} \mathrm{C} \\ \times 0.10^{\circ} \mathrm{C} & \bigcirc 40.10^{\circ} \mathrm{C} \\ -10.00^{\circ} \mathrm{C} & \square 50.00^{\circ} \mathrm{C} \\ -19.00^{\circ} \mathrm{C} & \triangle 60.00^{\circ} \mathrm{C}\end{array}$

(a)

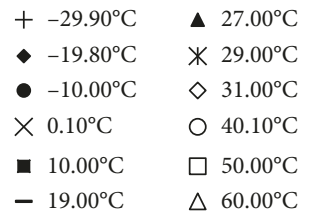

(b)

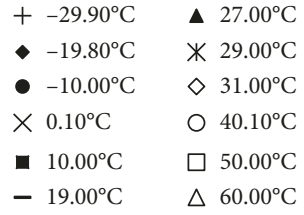

(c)

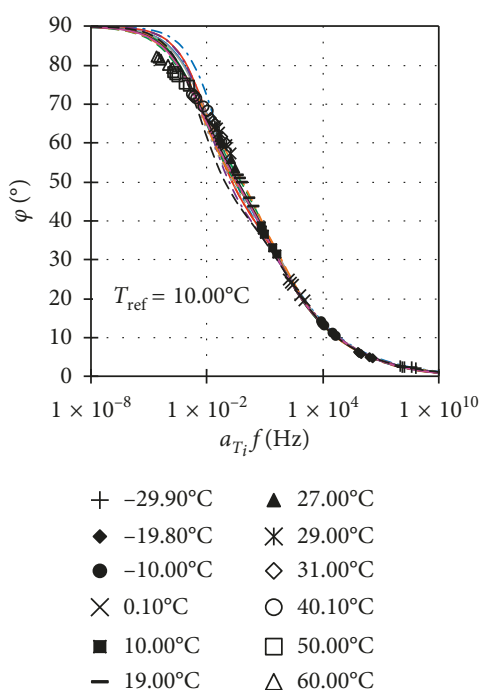

(d)

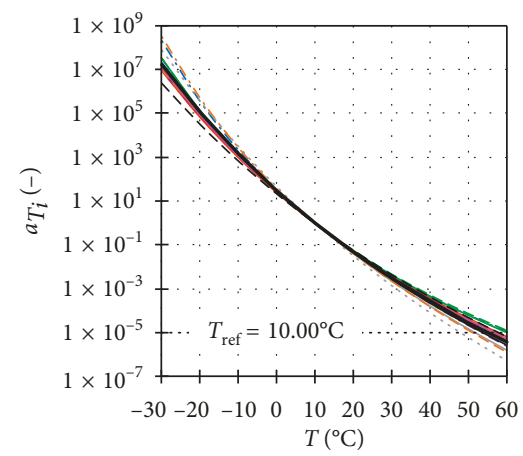

(e)
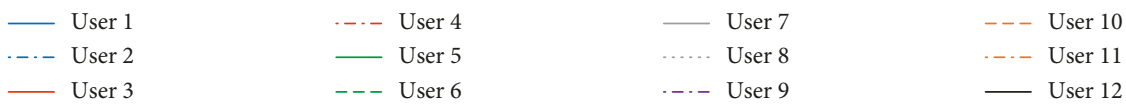

- User 13 - - - User 14

FIGURE 4: Results of 2S2P1D calibration panel for the bitumen: (a) Black space; (b) Cole-Cole plan; (c) master curves of $\left|G^{*}\right|$ at $10.00^{\circ} \mathrm{C}$; (d) master curves of $\varphi$ at $10.00^{\circ} \mathrm{C}$; (e) WLF equation used by users to obtain master curves in (c and d) and average WLF curve.

the global error parameters are affected by the high relative errors found at low frequency/high temperature. As already discussed, in this part of the frequency spectrum, the relative errors are not particularly important, given the low values of $G_{1}, G_{2}$, and $\left|G^{*}\right|$ (lower than $100 \mathrm{kPa}$ ).

Finally, overall error parameters were calculated for the whole calibration panel by averaging errors obtained for the 14 users, according to equations (22)-(29). The obtained parameters $\left(\widehat{\delta_{G_{1}}}, \widehat{\delta_{G_{2}}}, \widehat{\delta_{\left|G^{*}\right|}}\right.$ and $\widehat{\delta_{\varphi}} ; \widehat{\Delta_{G_{1}}}$, $\widehat{\Delta_{G_{2}}}, \widehat{\Delta_{\mid G^{*}}}$, and $\widehat{\Delta_{\varphi}}$ for absolute values of errors) and corresponding standard deviations $\left(\widehat{\mu_{G_{1}}}, \widehat{\mu_{G_{2}}}, \widehat{\mu_{\mid G^{*}}}\right.$, and $\widehat{\mu_{\varphi}}$; $\widehat{M_{G_{1}}}, \widehat{M_{G_{2}}}, \widehat{M_{\mid G^{*}} \mid}$, and $\widehat{M}_{\varphi}$ for absolute values of errors) are reported in Table 2.

$$
\begin{aligned}
& \widehat{\delta_{G_{1}}}=\frac{\sum_{i} \sum_{a_{\mathrm{T}_{i}} \omega} \delta_{G_{1_{i}}}\left(a_{T_{i}} \omega\right)}{14 N}, \\
& \widehat{\mu_{G_{1}}}=\sqrt{\frac{\sum_{i} \sum_{a_{\mathrm{T}_{i}}}\left[\delta_{G_{i}}\left(a_{T_{i}} \omega\right)-\widehat{\delta_{G_{1_{i}}}}\right]^{2}}{14 N},} \\
& \widehat{\delta_{G_{2}}}=\frac{\sum_{i} \sum_{a_{\mathrm{T}_{i}} \omega} \delta_{G_{2_{i}}}\left(a_{\mathrm{T}_{i}} \omega\right)}{14 N}, \\
& \widehat{\mu_{G_{2}}}=\sqrt{\frac{\sum_{i} \sum_{a_{\mathrm{T}_{i}}}\left[\delta_{G_{2_{i}}}\left(a_{T_{i}} \omega\right)-\widehat{\delta_{G_{2_{i}}}}\right]^{2}}{14 N}},
\end{aligned}
$$



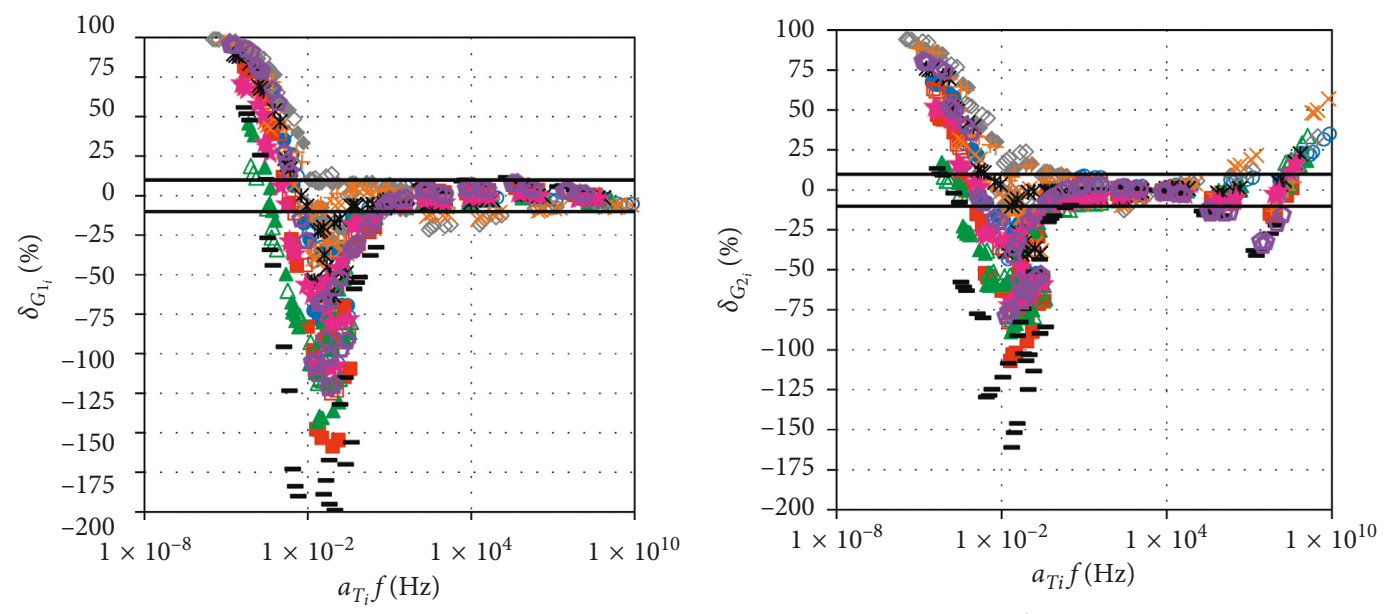

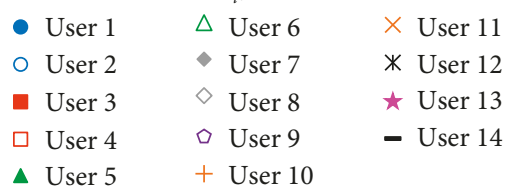

(a)

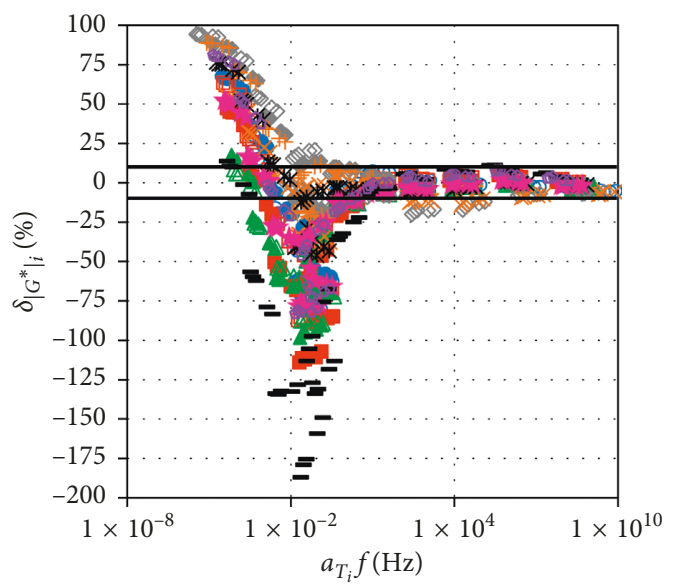

- User 1

- User 2

- User 3

$\square$ User 4

\ User 5
$\begin{array}{ll}\Delta \text { User 6 } & \times \text { User 11 } \\ \bullet \text { User 7 } & \star \text { User 12 } \\ \diamond \text { User 8 } & \star \text { User 13 } \\ \square \text { User 9 } & - \text { User 14 } \\ + \text { User 10 } & \end{array}$

(c)
- User 1
$\triangle$ User 6
$\times$ User 11
- User 2
- User 3
User 4
- User 7
* User 12
- User 5
- User 8
- User 9
+ User 10

(b)

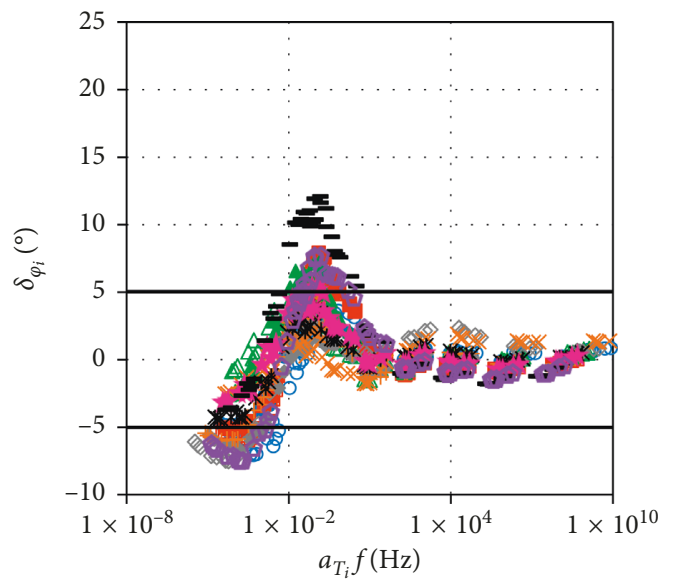
- User 1
$\triangle$ User 6
$\times$ User 11
- User 2
- User 7
* User 12
- User 3
$\diamond$ User 8
$\star$ User 13
․ User 4
- User 9
- User 14
^ User 5

(d)

FIGURE 5: Errors between 2S2P1D simulations of all users and experimental data for the bitumen $\left(T_{\text {ref }}=10.00^{\circ} \mathrm{C}\right)$ : relative errors for $G_{1}$ (a), $G_{2}\left(\right.$ b), and $\left|G^{*}\right|$ (c) and absolute error for $\varphi(\mathrm{d})$. Bold lines represent $10 \%$ and $5^{\circ}$ limits for, respectively, relative and absolute errors.

$$
\begin{aligned}
& \widehat{\delta_{\left|G^{*}\right|}}=\frac{\sum_{i} \sum_{a_{\mathrm{T}_{i}} \omega} \delta_{\left|G^{*}\right|_{i}}\left(a_{T_{i}} \omega\right)}{14 N}, \\
& \widehat{\mu_{\left|G^{*}\right|}}=\sqrt{\frac{\sum_{i} \sum_{a_{\mathrm{T}_{i}} \omega}\left[\delta_{\left|G^{*}\right|_{i}}\left(a_{\mathrm{T}_{i}} \omega\right)-\widehat{\delta_{\left|G^{*}\right|_{i}}}\right]^{2}}{14 N}},
\end{aligned}
$$

$$
\begin{aligned}
& \widehat{\delta_{\varphi}}=\frac{\sum_{i} \sum_{a_{\mathrm{T}_{i}} \omega} \delta_{\varphi_{i}}\left(a_{\mathrm{T}_{i}} \omega\right)}{14 N}, \\
& \widehat{\mu_{\varphi}}=\sqrt{\frac{\sum_{i} \sum_{a_{\mathrm{T}_{i}} \omega}\left[\delta_{\varphi_{i}}\left(a_{\mathrm{T}_{i}} \omega\right)-\widehat{\delta_{\varphi_{i}}}\right]^{2}}{14 N}},
\end{aligned}
$$




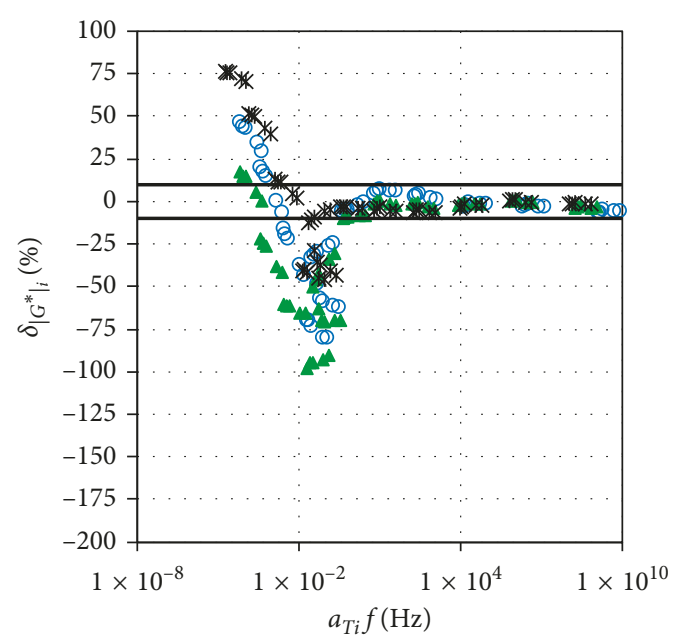

- User 2

- User 5

* User 12

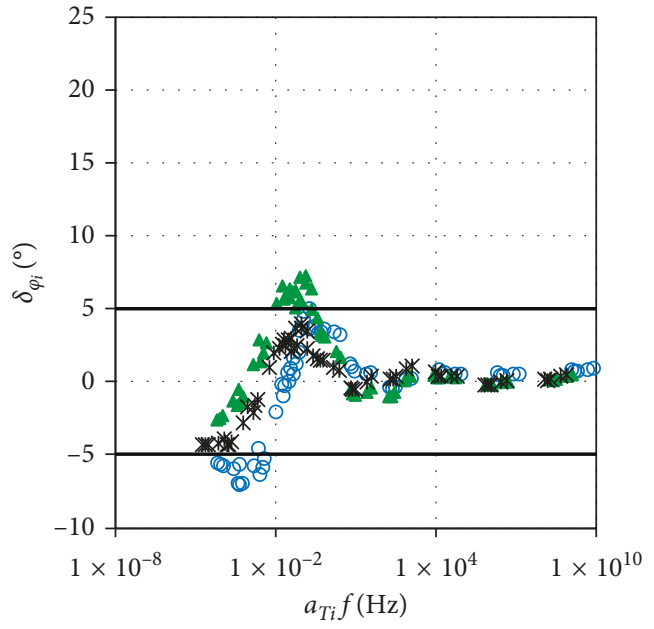

- User 2

\ User 5

* User 12

(a)

(b)

FIGURE 6: Errors between 2S2P1D simulations of the three most experienced users of the panel and experimental data for the bitumen $\left(T_{\text {ref }}=10.00^{\circ} \mathrm{C}\right)$ : relative error $\left|G^{*}\right|(\mathrm{a})$ and absolute errors for $\varphi(\mathrm{b})$. Bold lines represent $10 \%$ and $5^{\circ}$ limits for, respectively, relative and absolute errors.

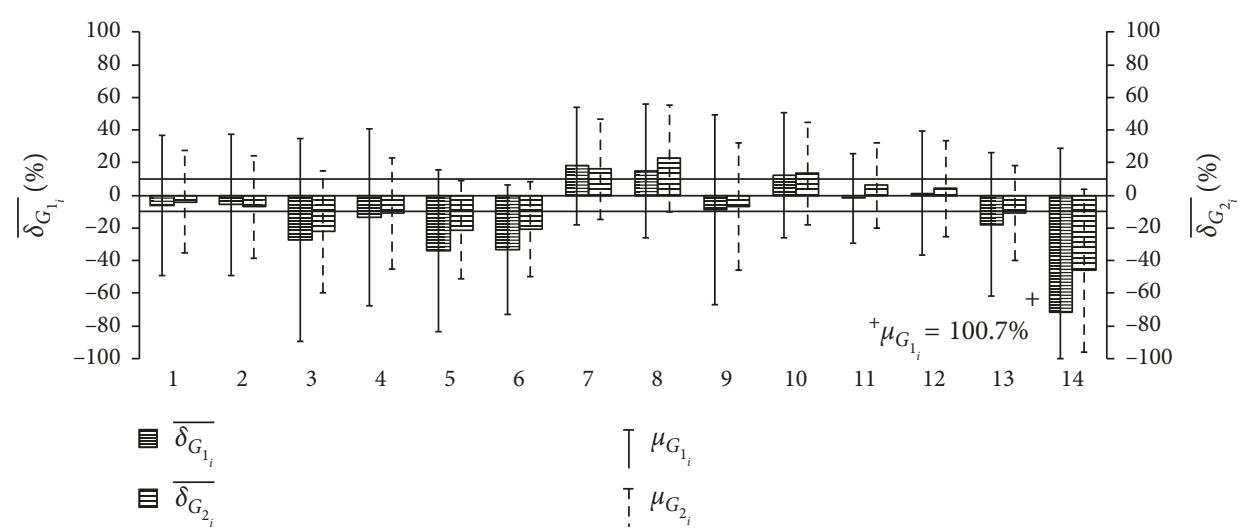

(a)

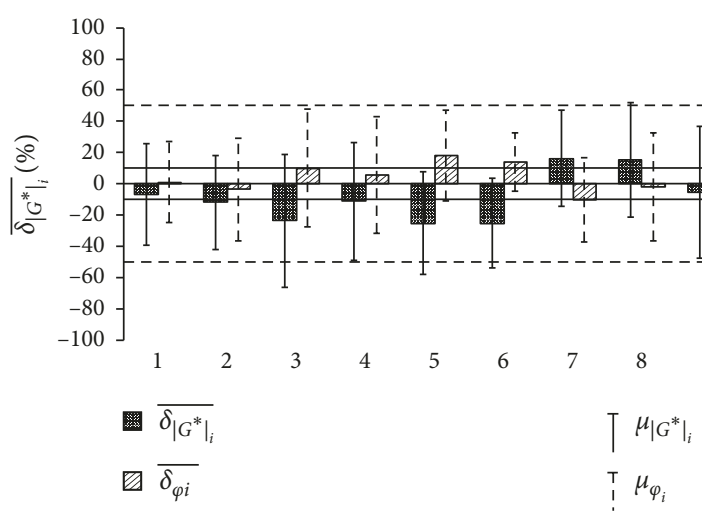

(b)

Figure 7: Histograms of global errors of 2S2P1D model fitting of all users for the bitumen (Figure 4), calculated according to equations (14)-(17): (a) relative errors for $G_{1}$ and $G_{2}\left(\overline{\delta_{G_{1_{j}}}}\right.$ and $\overline{\delta_{G_{2}}}$, respectively); (b) relative error for $\left|G^{*}\right|\left(\left.\overline{\delta_{\mid G^{*}}}\right|_{i}\right)$ and absolute error for $\varphi\left(\overline{\delta_{\varphi_{i}}}\right)$. Error bars are plotted according to standard deviations $\mu_{G_{1_{i}}}, \mu_{G_{2_{i}}}, \mu_{\left|G^{*}\right|}$, and $\mu_{\varphi_{i}}$. 


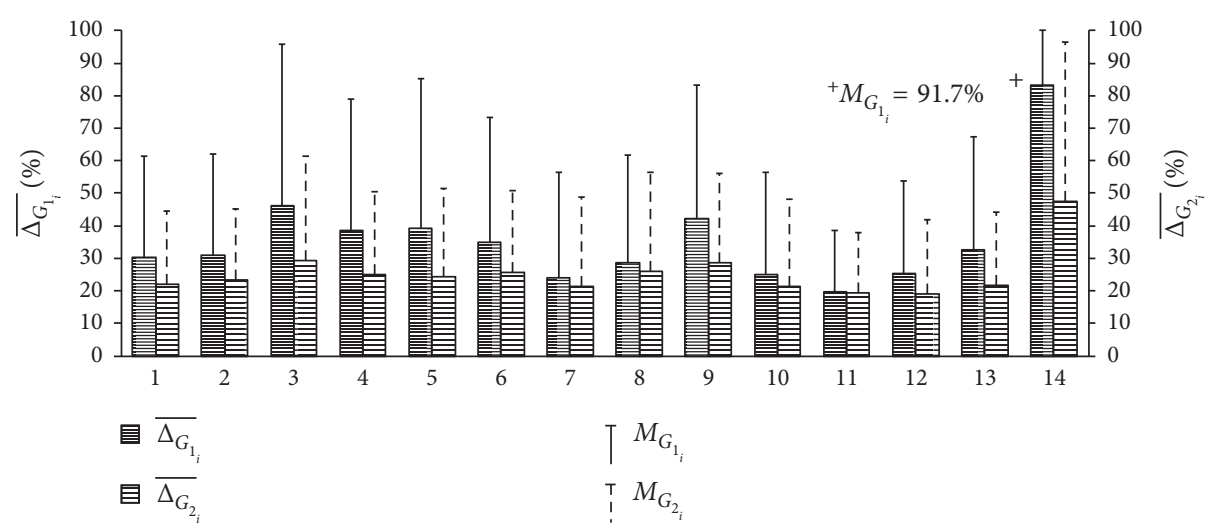

(a)

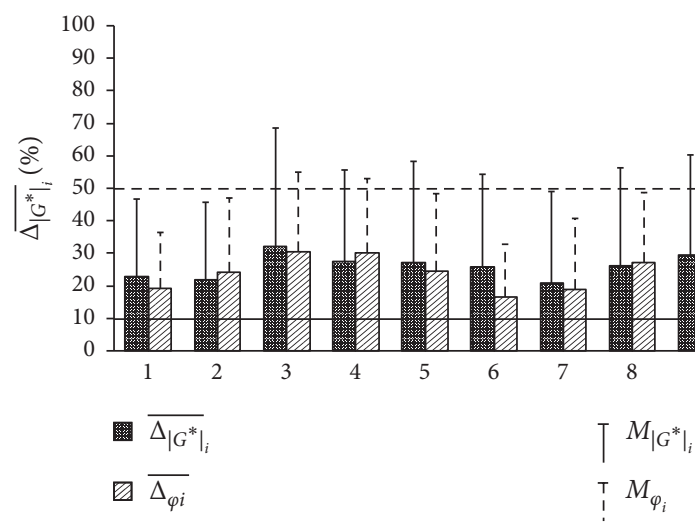

(b)

FIgURE 8: Histograms of global errors of 2S2P1D model fitting of all users for the bitumen (Figure 4), calculated according to equations (18)-(21): (a) relative errors for $G_{1}$ and $G_{2}\left(\overline{\Delta_{G_{1}}}\right.$ and $\overline{\Delta_{G_{2}}}$, respectively); (b) relative error for $\left|G^{*}\right|\left(\overline{\Delta_{\left|G^{*}\right|_{i}}}\right)$ and absolute error for $\varphi\left(\overline{\Delta_{\varphi_{i}}}\right)$. Error bars are plotted according to standard deviations $M_{G_{l_{i}}}, M \mu_{G_{2 i}}, M \mu_{\mid G^{*}{ }_{i}}$, and $M_{\varphi_{i}}$.

TABLE 2: Overall global errors of 2S2P1D model fitting for a bitumen, calculated for the whole calibration panel according to equations (22)-(29).

\begin{tabular}{|c|c|c|c|c|c|c|c|c|c|c|c|c|c|c|c|}
\hline$\widehat{\delta_{G_{1}}}$ & $\widehat{\mu_{G_{1}}}$ & $\widehat{\delta_{G_{2}}}$ & $\widehat{\mu_{G_{2}}}$ & $\widehat{\delta_{\left|G^{*}\right|}}$ & $\widehat{\mu_{\left|G^{*}\right|}}$ & $\widehat{\delta_{\varphi}}$ & $\widehat{\mu_{\varphi}}$ & $\widehat{\Delta_{G_{1}}}$ & $\widehat{M_{G_{1}}}$ & $\widehat{\Delta_{G_{2}}}$ & $\widehat{M_{G_{2}}}$ & $\widehat{\Delta_{\left|G^{*}\right|}}$ & $\widehat{M_{\left|G^{*}\right|}}$ & $\widehat{\Delta_{\varphi}}$ & $\widehat{M}_{\varphi}$ \\
\hline$-12.46 \%$ & $56.13 \%$ & $-6.27 \%$ & $37.86 \%$ & $-9.05 \%$ & $40.49 \%$ & $0.60^{\circ}$ & $3.40^{\circ}$ & $35.80 \%$ & $44.99 \%$ & $25.36 \%$ & $28.80 \%$ & $26.39 \%$ & $32.02 \%$ & $2.49^{\circ}$ & $2.39^{\circ}$ \\
\hline
\end{tabular}

$$
\begin{aligned}
\widehat{\Delta_{G_{1}}} & =\frac{\sum_{i} \sum_{a_{\mathrm{T}_{i}}}\left|\delta_{G_{1_{i}}}\left(a_{\mathrm{T}_{i}} \omega\right)\right|}{14 N}, \\
\widehat{M_{G_{1}}} & =\sqrt{\frac{\left.\sum_{i} \sum_{a_{\mathrm{T}_{i}}} \omega\left|\delta_{G_{1_{i}}}\left(a_{\mathrm{T}_{i}} \omega\right)\right|-\widehat{\Delta_{G_{1_{i}}}}\right]^{2}}{14 N}}, \\
\widehat{\Delta_{G_{2}}} & =\frac{\sum_{i} \sum_{a_{\mathrm{T}_{i}} \omega}\left|\delta_{G_{2_{i}}}\left(a_{\mathrm{T}_{i}} \omega\right)\right|}{14 N}, \\
\widehat{M_{G_{2}}} & =\sqrt{\frac{\left.\sum_{i} \sum_{a_{\mathrm{T}_{i}}} \omega\left|\delta_{G_{2_{i}}}\left(a_{\mathrm{T}_{i}} \omega\right)\right|-\widehat{\Delta_{G_{2_{i}}}}\right]^{2}}{14 N}},
\end{aligned}
$$

$$
\begin{aligned}
\widehat{\Delta_{\left|G^{*}\right|}} & =\frac{\sum_{i} \sum_{a_{\mathrm{T}_{i}} \omega}\left|\delta_{\left|G^{*}\right|_{i}}\left(a_{\mathrm{T}_{i}} \omega\right)\right|}{14 N}, \\
\widehat{M_{\left|G^{*}\right|}} & =\sqrt{\frac{\sum_{i} \sum_{a_{\mathrm{T}_{i}} \omega}\left[\left|\delta_{\left|G^{*}\right|_{i}}\left(a_{\mathrm{T}_{i}} \omega\right)\right|-\widehat{\left.\Delta_{\mid G^{*}}\right|_{i}}\right]^{2}}{14 N}}, \\
\widehat{\Delta_{\varphi}} & =\frac{\sum_{i} \sum_{a_{\mathrm{T}_{i}} \omega \mid}\left|\delta_{\varphi_{i}}\left(a_{\mathrm{T}_{i}} \omega\right)\right|}{14 N}, \\
\widehat{M_{\varphi}} & =\sqrt{\frac{\sum_{i} \sum_{a_{\mathrm{T}_{i}}} \omega\left[\left|\delta_{\varphi_{i}}\left(a_{\mathrm{T}_{i}} \omega\right)\right|-\widehat{\Delta_{\varphi_{i}}}\right]^{2}}{14 N}} .
\end{aligned}
$$


TABLE 3: WLF and 2S2P1D constants obtained for the bituminous mixture by all the users of the calibration panel $\left(T_{\text {ref }}=9.53^{\circ} \mathrm{C}\right)$.

\begin{tabular}{lcccccccccc}
\hline & $C_{1}(-)$ & $C_{2}\left({ }^{\circ} \mathrm{C}\right)$ & $E_{00}(\mathrm{MPa})$ & $E_{0}(\mathrm{MPa})$ & $\delta(-)$ & $k(-)$ & $h(-)$ & $\beta(-)$ & $\tau(\mathrm{s})$ & $\log \tau(-)$ \\
\hline User 1 & 23.42 & 154.38 & 26 & 40700 & 2.26 & 0.189 & 0.593 & 180 & $2.10 \times 10^{-1}$ & -0.68 \\
User 2 & 26.20 & 170.02 & 20 & 40900 & 2.00 & 0.185 & 0.545 & 400 & $1.00 \times 10^{-1}$ & -1.00 \\
User 3 & 30.63 & 203.51 & 20 & 41300 & 1.95 & 0.178 & 0.563 & 200 & $9.00 \times 10^{-2}$ & -1.05 \\
User 4 & 23.93 & 158.02 & 20 & 40850 & 2.13 & 0.185 & 0.565 & 230 & $1.00 \times 10^{-1}$ & -1.00 \\
User 5 & 22.75 & 156.29 & 13 & 40500 & 2.30 & 0.195 & 0.600 & 800 & $1.50 \times 10^{-1}$ & -0.82 \\
User 6 & 19.80 & 135.00 & 25 & 40500 & 2.10 & 0.190 & 0.550 & 180 & $9.50 \times 10^{-2}$ & -1.02 \\
User 7 & 31.07 & 199.78 & 18 & 40800 & 2.15 & 0.188 & 0.560 & 230 & $9.00 \times 10^{-2}$ & -1.05 \\
User 8 & 30.86 & 196.09 & 14 & 41000 & 2.10 & 0.179 & 0.610 & 200 & $1.40 \times 10^{-1}$ & -0.85 \\
User 9 & 35.17 & 238.76 & 23 & 41000 & 2.00 & 0.180 & 0.550 & 180 & $9.00 \times 10^{-2}$ & -1.05 \\
User 10 & 37.95 & 238.01 & 23 & 41000 & 2.15 & 0.185 & 0.580 & 230 & $2.50 \times 10^{-1}$ & -0.60 \\
User 11 & 25.41 & 170.77 & 18 & 40850 & 2.15 & 0.189 & 0.595 & 250 & $1.40 \times 10^{-1}$ & -0.85 \\
User 12 & 25.67 & 172.20 & 19 & 40500 & 2.30 & 0.193 & 0.593 & 240 & $1.30 \times 10^{-1}$ & -0.89 \\
User 13 & 20.28 & 134.42 & 15 & 40700 & 2.30 & 0.190 & 0.620 & 1000000 & $1.70 \times 10^{-1}$ & -0.77 \\
User 14 & 27.89 & 189.50 & 16 & 41000 & 2.28 & 0.188 & 0.595 & 320 & $1.10 \times 10^{-1}$ & -0.96 \\
\hline Mean & 27.22 & 179.77 & 19 & 40829 & 2.16 & 0.187 & 0.580 & $71689^{\mathrm{a}}$ & $1.33 \times 10^{-1}$ & -0.90 \\
St. dev. & 5.36 & 33.00 & 4 & 233 & 0.12 & 0.005 & 0.024 & $267186^{\mathrm{b}}$ & $4.89 \times 10^{-2}$ & 0.14 \\
COV & $19.70 \%$ & $18.36 \%$ & $20.68 \%$ & $0.57 \%$ & $5.56 \%$ & $2.71 \%$ & $4.18 \%$ & $372.7 \% \%^{\mathrm{c}}$ & $36.70 \%$ & $-15.96 \%$ \\
\hline
\end{tabular}

Note. Coefficient of variation (COV): standard deviation/mean. ${ }^{a} 280$, if the unusually high value of $\beta$ of user 13 is ignored. ${ }^{\mathrm{b}} 168$, if the unusually high value of $\beta$ of user 13 is ignored. ${ }^{\mathrm{c}} 60.0 \%$, if the unusually high value of $\beta$ of user 13 is ignored.

4.2. 2S2P1D Fitting for a Bituminous Mixture. Table 3 reports values of WLF and 2S2P1D constants obtained by all users of the calibration panel for the bituminous mixture. Figure 9 shows a comparison of the simulations of the LVE behaviour of the mixture obtained by all the users and the experimental data points. In particular, Figures 9(a) and 9(b) show, respectively, Black and Cole-Cole spaces, Figures 9(c) and 9 (d) show master curves of, respectively, $\left|E^{*}\right|$ and $\varphi$, and Figure 9(e) shows the various WLF curves obtained by the users, together with the average WLF curve, according to the constants shown in Table 3. As for bitumen in Section 4.1, experimental points shown in master curves of Figures 9(c) and $9(\mathrm{~d})$ are shifted using shift factors calculated with the mentioned average WLF curve, in order to have a graphical representation.

A very low value $(0.57 \%)$ is found for the COV of $E_{00}$. Also, similarly to what was found for the bitumen, COV of constants $k$ and $h$ is quite low (lower than 5\%). If the unusually high value of $\beta$ chosen by user 13 is neglected, the COV for this constant is equal to $60.0 \%$, of the same order of magnitude of the COV for the same constant found for the bitumen. Concerning this point, it should be highlighted that the value of $\beta$ is directly related to the viscosity of the linear dashpot of the analogical model. For this reason, its variations should be considered in logarithmic scale; that is, a variation of this constant from 100 to 200 has a more important effect on the LVE simulation than a variation from 900 to 1000 . In the case of the 2S2P1D fitting carried out by user 13, it can be easily verified that a relatively small variation occurs to the corresponding simulation if the value of $\beta$ is fixed to 1000 instead of 1000000 .

Overall, one important conclusion that can be drawn from the results of the calibration panel is that the variability (expressed by the COV) of constants $G_{00}$ (for the bitumen), $E_{00}$ and $E_{0}$ (for the mixture), $\delta, k, h$, and $\log \tau$ (for both) is approximately equal or lower than $20 \%$.
2S2P1D simulations of all users satisfactorily approximate experimental points. At very low frequency/high temperature (less than $10^{-3} \mathrm{~Hz}$ ), a negligible underestimation of $\left|E^{*}\right|$ and $\varphi$ is observed for all users. However, these differences are negligible in absolute value (less than $20 \mathrm{MPa}$ for $\left|E^{*}\right|$ ) and concern only very few experimental points of the isotherms obtained at $38.83^{\circ} \mathrm{C}$. As in the case of the bitumen, satisfactory fitting of experimental data is observed over the whole spans of equivalent frequencies (between $10^{-6}$ and $10^{10} \mathrm{~Hz}$ at the reference temperature of $9.5^{\circ} \mathrm{C}$ ) and $\left|E^{*}\right|$ (between 10 and $40000 \mathrm{MPa}$ ).

Similarly to what was done for the bitumen, relative errors $\delta_{E_{1_{i}}}, \delta_{E_{2 i}}$, and $\delta_{\left|E^{*}\right|_{i}}$ (respectively, for $E_{1}, E_{2}$, and $\left|E^{*}\right|$ ) and absolute error $\delta_{\varphi_{i}}$ (for $\varphi$ ) were calculated for each equivalent frequency $a_{\mathrm{T}_{i}} \omega$ (55 data points) according to the following equations:

$$
\begin{aligned}
\delta_{E_{1_{i}}}\left(a_{\mathrm{T}_{i}} \omega\right) & =\frac{E_{1, \exp }\left(a_{\mathrm{T}_{i}} \omega\right)-E_{1,2 \mathrm{~S} 2 \mathrm{P} 1 \mathrm{D}_{i}}\left(a_{\mathrm{T}_{i}} \omega\right)}{E_{1, \exp }\left(a_{\mathrm{T}_{i}} \omega\right)}, \\
\delta_{E_{2_{i}}}\left(a_{\mathrm{T}_{i}} \omega\right) & =\frac{E_{2, \exp }\left(a_{\mathrm{T}_{i}} \omega\right)-E_{2,2 \mathrm{~S} 2 \mathrm{P} 1 \mathrm{D}_{i}}\left(a_{\mathrm{T}_{i}} \omega\right)}{E_{2, \exp }\left(a_{\mathrm{T}_{i}} \omega\right)}, \\
\delta_{\left|E^{*}\right|_{i}}\left(a_{\mathrm{T}_{i}} \omega\right) & =\frac{\left|E_{\exp }^{*}\right|\left(a_{\mathrm{T}_{i}} \omega\right)-\left|E_{2 \mathrm{~S} 2 \mathrm{P} 1 \mathrm{D}_{i}}^{*}\right|\left(a_{\mathrm{T}_{i}} \omega\right)}{\left|E_{\exp }^{*}\right|\left(a_{\mathrm{T}_{i}} \omega\right)}, \\
\delta_{\varphi_{i}}\left(a_{\mathrm{T}_{i}} \omega\right) & =\varphi_{\exp }\left(a_{\mathrm{T}_{i}} \omega\right)-\varphi_{2{\mathrm{~S} 2 \mathrm{P} 1 \mathrm{D}_{i}}_{i}}\left(a_{\mathrm{T}_{i}} \omega\right),
\end{aligned}
$$

where the variables are listed as follows: $E_{1, \exp }\left(a_{\mathrm{T}_{i}} \omega\right)$, $E_{2, \exp }\left(a_{\mathrm{T}_{j}} \omega\right),\left|E_{\text {exp }}^{*}\right|\left(a_{\mathrm{T}_{i}} \omega\right)$, and $\varphi_{\exp }\left(a_{\mathrm{T}_{i}} \omega\right)$ are experimental values of, respectively, $E_{1}, E_{2},\left|E^{*}\right|$, and $\varphi$ at the equivalent frequency $a_{\mathrm{T}_{i}} \omega ; E_{1,2 \mathrm{~S} 2 \mathrm{P}_{1} \mathrm{D}_{i}}\left(a_{\mathrm{T}_{i}} \omega\right), E_{2,2 \mathrm{~S}_{\mathrm{P} 1 \mathrm{P}_{i}}}\left(a_{\mathrm{T}_{i}} \omega\right),\left|E_{2 \mathrm{~S} 2 \mathrm{P} 1 \mathrm{D}_{i}}^{*}\right|$ $\left(a_{\mathrm{T}_{i}} \omega\right)$, and $\varphi_{2 \mathrm{~S}_{2 \mathrm{P} 1 \mathrm{D}}}\left(a_{\mathrm{T}_{i}} \omega\right)$ are values of, respectively, $E_{1}, E_{2}$, $\left|E^{*}\right|$, and $\varphi$ at the equivalent frequency $a_{\mathrm{T}_{i}} \omega$, calculated with the 2S2P1D according to the constants of the $i$-th user reported in Table 1. 


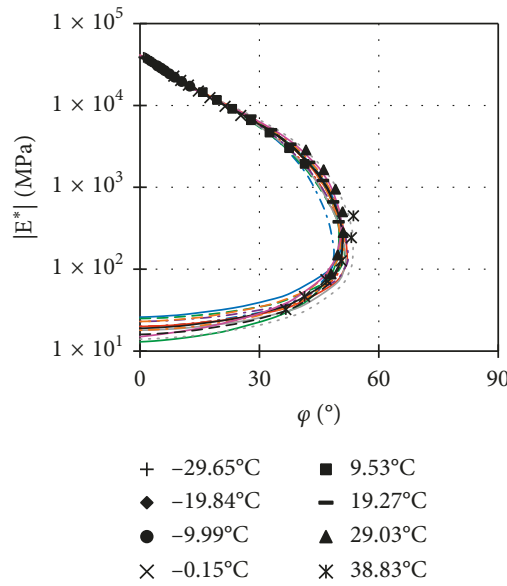

(a)

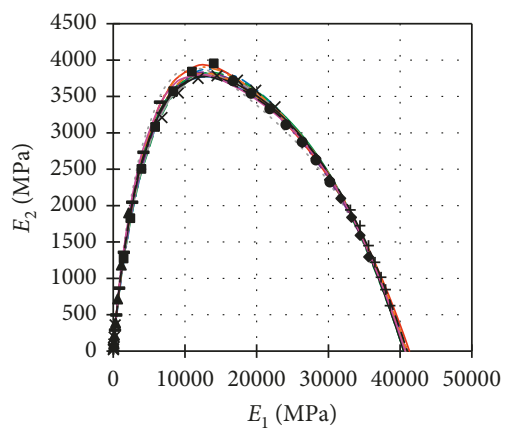

- $9.53^{\circ} \mathrm{C}$

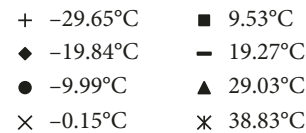

(b)

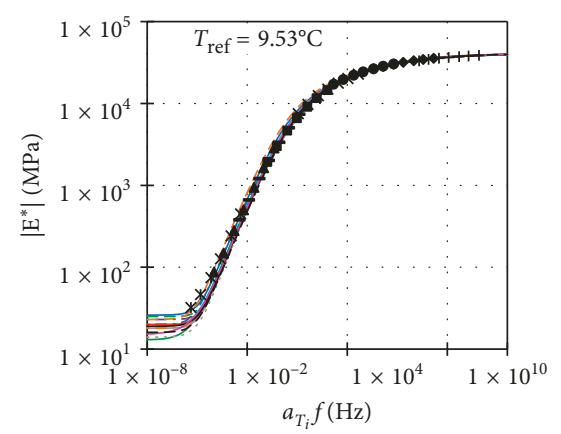

$$
\begin{array}{ll}
+-29.65^{\circ} \mathrm{C} & \text { - } 9.53^{\circ} \mathrm{C} \\
--19.84^{\circ} \mathrm{C} & -19.27^{\circ} \mathrm{C} \\
--9.99^{\circ} \mathrm{C} & \boldsymbol{\Delta} 29.03^{\circ} \mathrm{C} \\
\times-0.15^{\circ} \mathrm{C} & * 38.83^{\circ} \mathrm{C}
\end{array}
$$

(c)

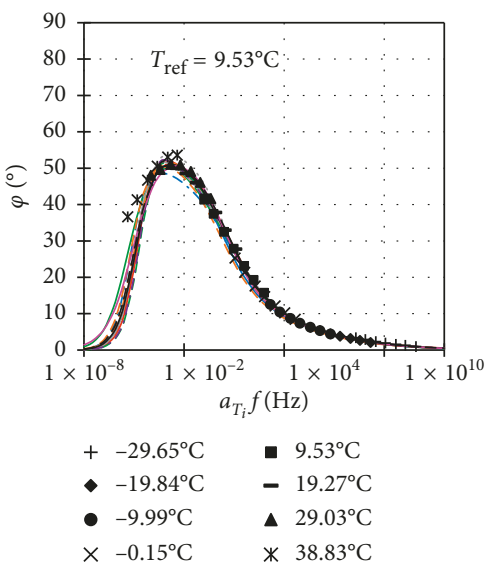

(d)

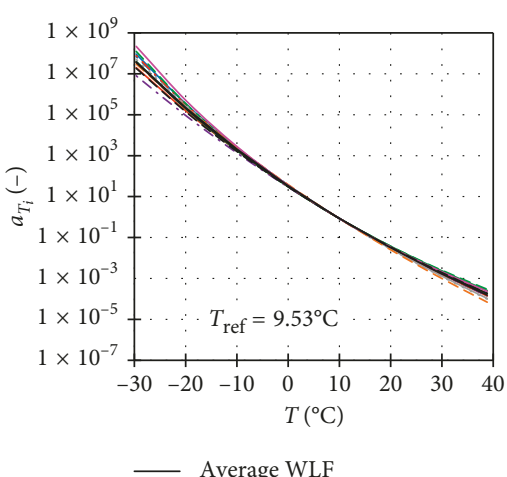

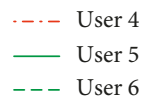

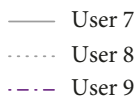

(e)

$\begin{array}{ll}\text {-. } & \text { User } 10 \\ \text {-.. } & \text { User } 11 \\ \text { - User } 12\end{array}$
- User 13

--- User 14

Figure 9: Results of 2S2P1D calibration panel for a mixture: (a) Cole-Cole plan; (b) Black space; (c) master curves of $\left|G^{*}\right|$ at $9.53^{\circ} \mathrm{C}$; (d) master curves of $\varphi$ at $9.53^{\circ} \mathrm{C}$; (e) WLF equation used by users to obtain master curves in (c and d) and average WLF curve.

Master curves of $\delta_{E_{1,}}, \delta_{E_{2 i}}, \delta_{\left|E^{*}\right| i}$, and $\delta_{\varphi_{i}}$ are shown in Figure 10 (10\% and $5^{\circ}$ limits for, respectively, relative and absolute errors are represented by bold lines). As in the case of the bitumen, errors $\delta_{E_{1}}, \delta_{E_{2}}, \delta_{\left|E^{*}\right| i}$, and $\delta_{\varphi_{i}}$ were calculated for each $i$-th user at equivalent frequencies obtained with shift factors $a_{\mathrm{T}_{i}}$ calculated according to his/her WLF constants shown in Table 3. Hence, master curves corresponding to different users have slightly different total ranges of equivalent frequencies. Differences greater than $5^{\circ}$ between experimental and simulated $\varphi$ (parameter $\delta_{\varphi_{i}}$ in Figure 10(d)) are observed only for the last two points of the isotherm at $38.83^{\circ} \mathrm{C}$. Concerning errors in the simulation of $E_{1}, E_{2}$, and $\left|E^{*}\right|$, for the majority of users, values greater than $10 \%$ of parameters $\delta_{E_{1 i}}, \delta_{E_{2}}$, and $\delta_{\left|E^{*}\right|_{i}}$ are observed only for equivalent frequencies lower than approximately $10^{-2} \mathrm{~Hz}$. Only for two users, values of 2S2P1D model simulations are significantly higher than experimental data for frequencies between $10^{-3}$ and $10^{2} \mathrm{~Hz}$. The important relative errors observed for $E_{2}$ at frequencies higher than $10^{5} \mathrm{~Hz}$ can be neglected because of the very low values of $E_{2}$ in this frequency range (lower than $2000 \mathrm{MPa}$ ) with respect to $\left|E^{*}\right|$ (higher than $30000 \mathrm{MPa}$ ). Similarly to what was done for the bitumen (Section 4.1), the master curves $\left(\right.$ at $\left.9.5^{\circ} \mathrm{C}\right)$ of $\delta_{\left|E^{*}\right|_{i}}$ and $\delta_{\varphi_{i}}$ obtained for the mixture by the three most experienced users $(2,5$, and 12) are plotted in Figure 11. Excellent correspondences between simulations and experimental data are observed, confirming the ability of the model to simulate LVE behaviour of mixtures.

Average values $\left(\overline{\delta_{E_{1}}}, \overline{\delta_{E_{2}}}, \overline{\delta_{\left|E^{*}\right|}}\right.$, and $\left.\overline{\delta_{\varphi_{i}}}\right)$ and standard deviations $\left(\mu_{E_{1}}, \mu_{E_{2}}, \mu_{\left|E^{*}\right| i}\right.$, and $\left.\mu_{\varphi_{i}}\right)$ of relative and absolute errors $\delta_{E_{1 i}}, \delta_{E_{2 i}} ; \delta_{\left|E^{*}\right|_{i}}$, and $\delta_{\varphi_{i}}$ of each user at the $N$ considered equivalent frequencies $a_{\mathrm{T}}(N=55)$ were calculated according to equations (34)-(37) and plotted in histograms of Figure 12. Error bars are plotted according to standard deviation values. 

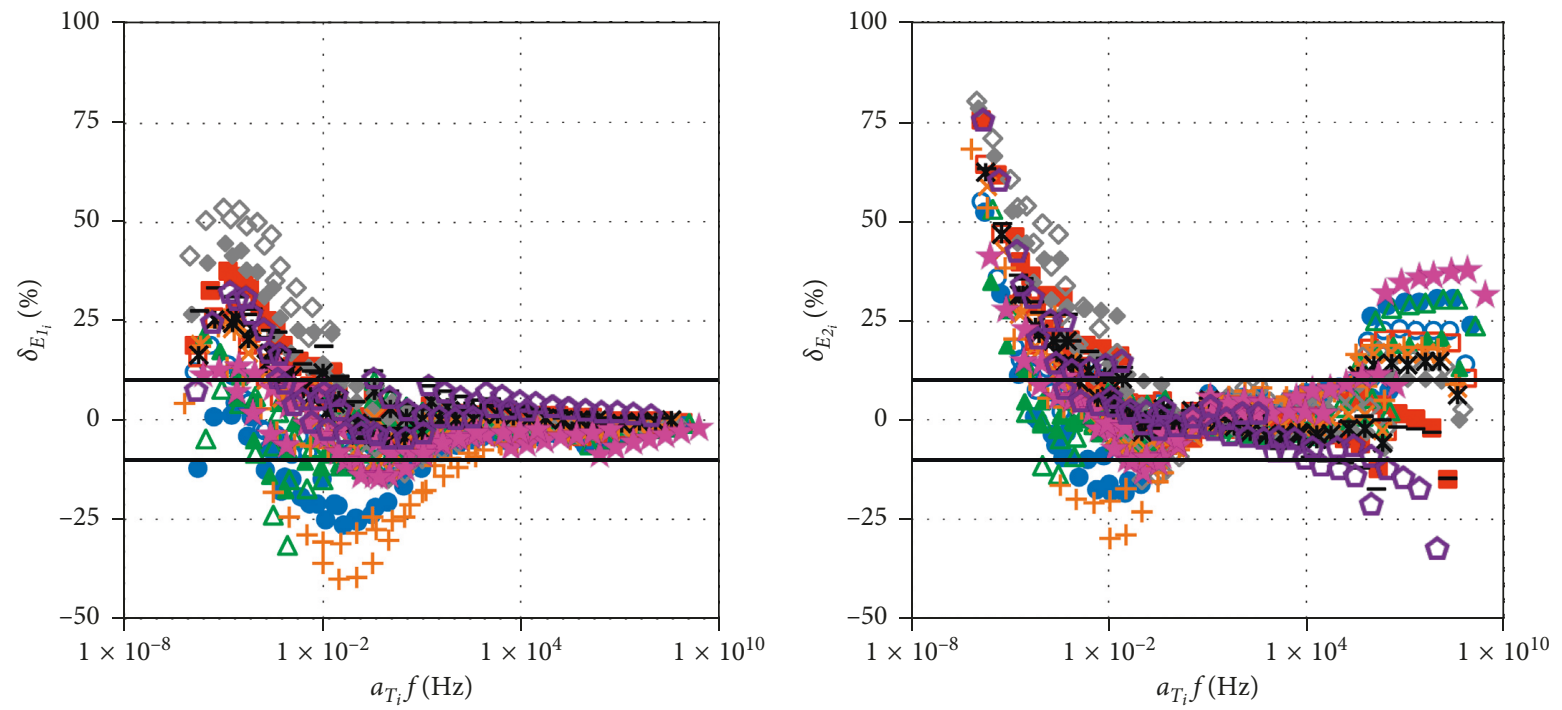
- User 1
- User 2
- User 3
$\square$ User 4
$\Delta$ User 5

\begin{abstract}
$\triangle$ User 6
- User 7

$\diamond$ User 8

+ User 10
\end{abstract}
$\checkmark$ User 9
$\times$ User 11
* User 12

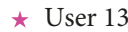
- User 14

(a)

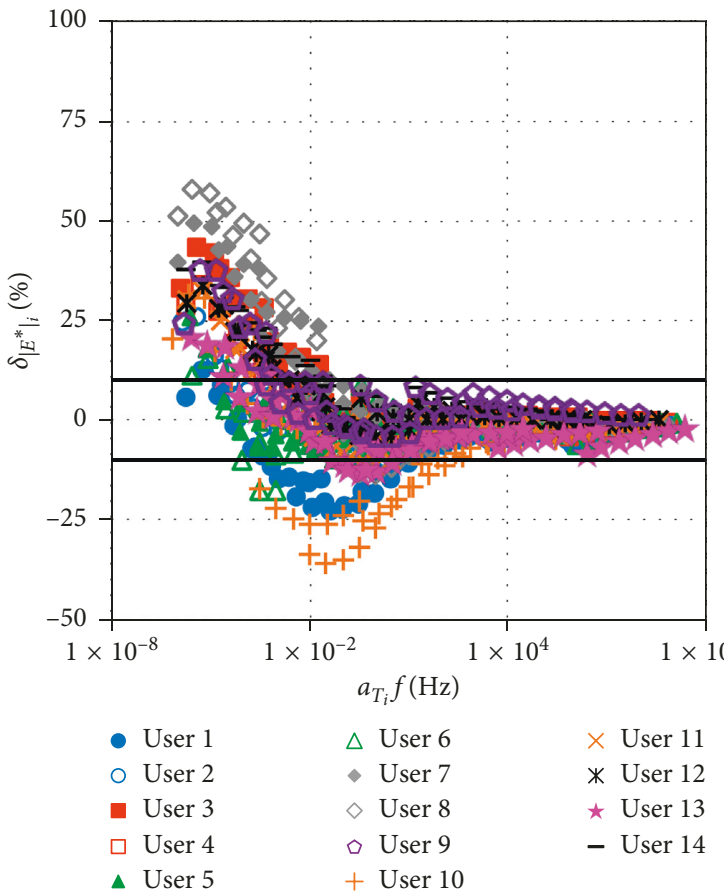

(c)
- User 1

- User 2

- User 3

$\square$ User 4

- User 5

$\times$ User 11

* User 12

* User 13

- User 14

(b)

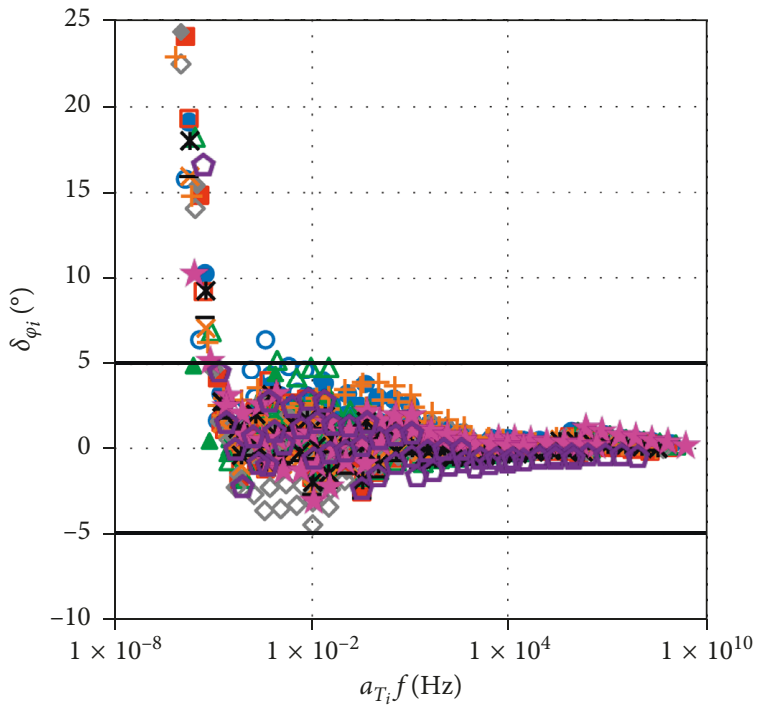
- User 1
$\triangle$ User 6
$\times$ User 11
- User 2
- User 7
* User 12
- User 3
$\star$ User 13
$\square$ User 4
- User 14
- User 9

(d)

Figure 10: Errors between 2S2P1D simulations of all users and experimental data for the bituminous mixture $\left(T_{\text {ref }}=9.53^{\circ} \mathrm{C}\right)$ : relative errors for $E_{1}(\mathrm{a}), E_{2}(\mathrm{~b})$, and $\left|E^{*}\right|$ (c) and absolute error for $\varphi(\mathrm{d})$. Bold lines represent $10 \%$ and $5^{\circ}$ limits for, respectively, relative and absolute errors. 


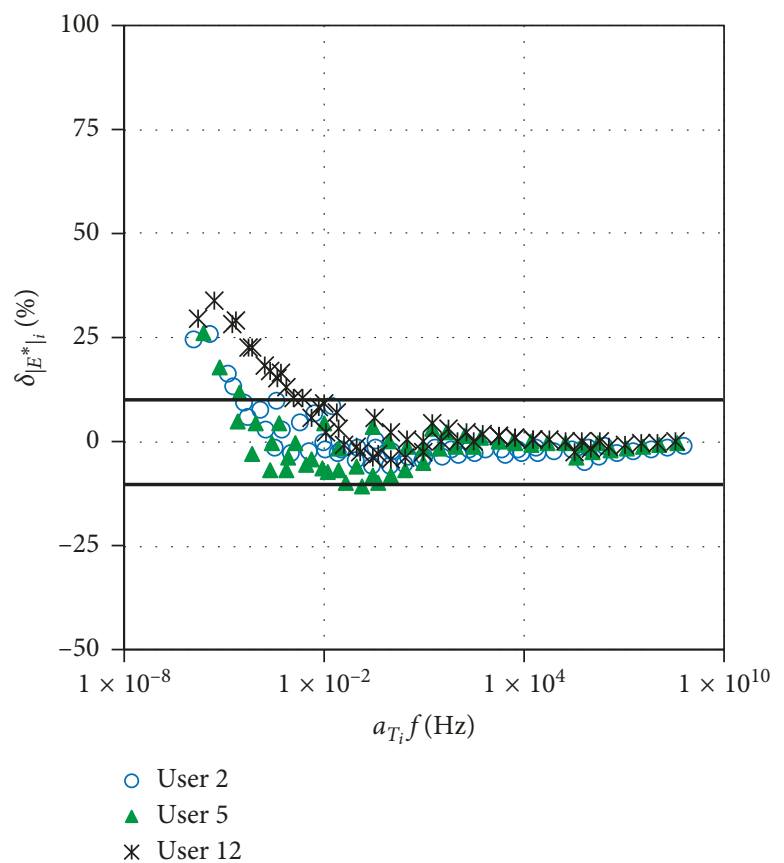

(a)

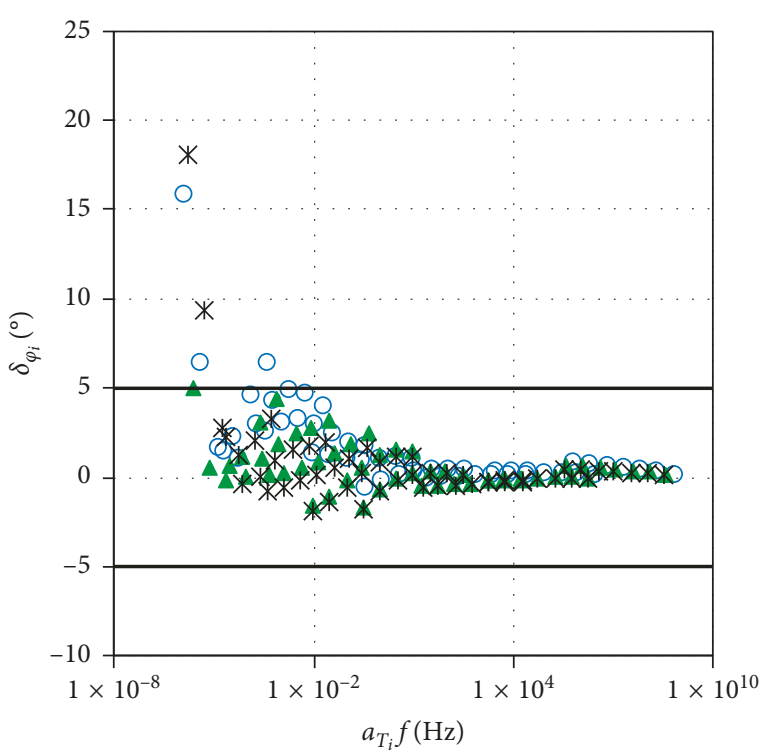

○ User 2

$\Delta$ User 5

* User 12

(b)

FIGURE 11: Errors between 2S2P1D simulations of the three most experienced users of the panel and experimental data for the bituminous mixture $\left(T_{\text {ref }}=9.53^{\circ} \mathrm{C}\right)$ : relative error for $\left|E^{*}\right|$ (a) and absolute error for $\varphi(\mathrm{b})$. Bold lines represent $10 \%$ and $5^{\circ}$ limits for, respectively, relative and absolute errors.

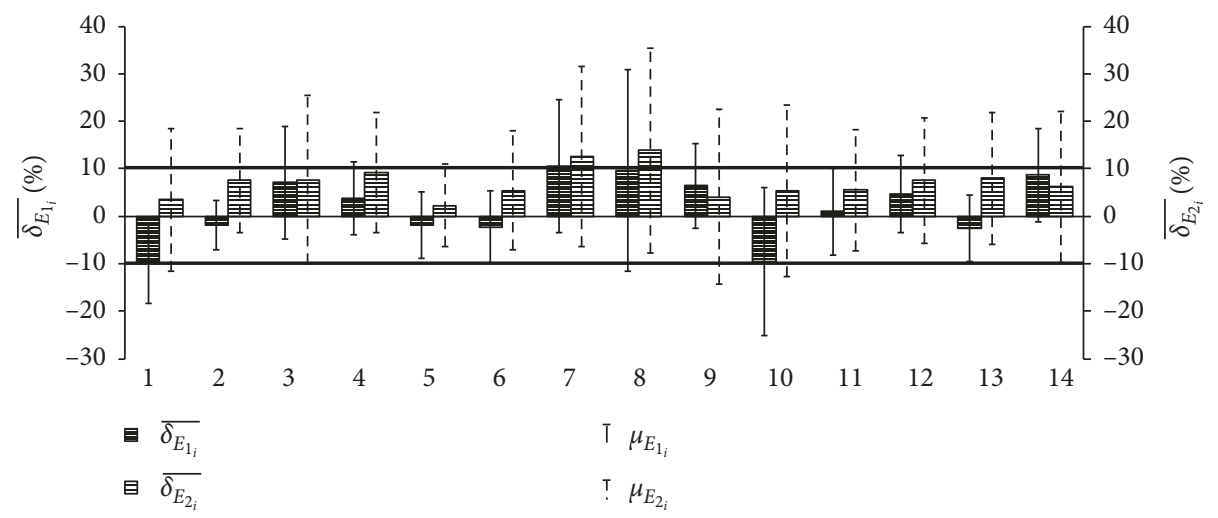

(a)

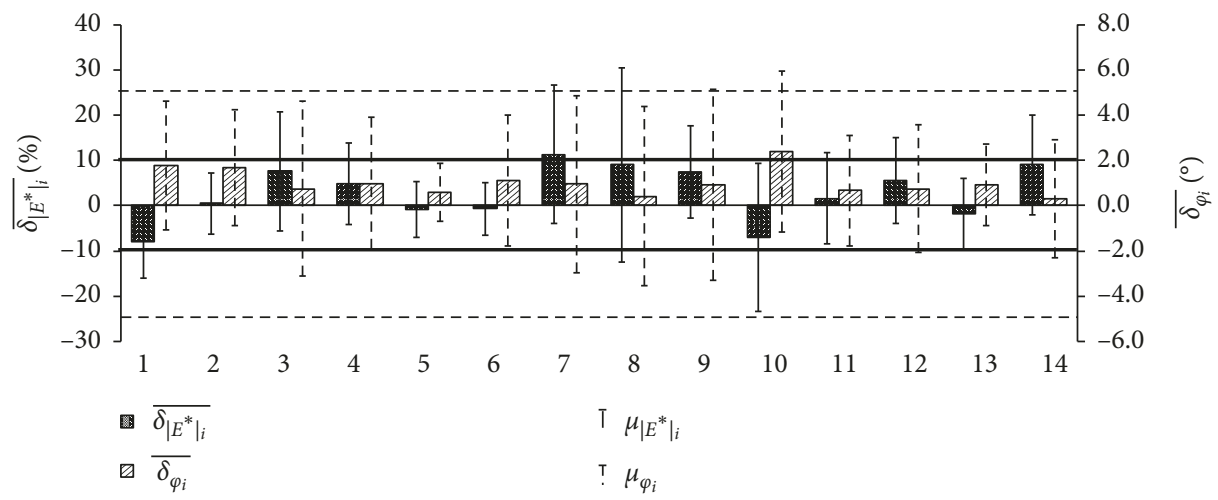

(b)

FIGURE 12: Histograms of global errors of 2S2P1D model fitting of all users for the bituminous mixture (Figure 9), calculated according to equations (34)-(37): (a) relative errors for $E_{1}$ and $E_{2}\left(\overline{\delta_{E_{1}}}\right.$ and $\overline{\delta_{E_{2}}}$, respectively); (b) relative error for $\left|E^{*}\right|\left(\overline{\delta_{\mid E^{*} i_{i}}}\right)$ and absolute error for $\varphi$ $\left(\overline{\delta_{\varphi_{i}}}\right)$. Error bars are plotted according to standard deviations $\mu_{E_{1_{i}}}, \mu_{E_{2_{i}}}, \mu_{\left|E^{*}\right|_{i}}$, and $\mu_{\varphi_{i}}$. 


$$
\begin{aligned}
& \overline{\delta_{E_{1_{i}}}}=\frac{\sum_{a_{\mathrm{T}_{i}} \omega} \delta_{E_{1_{i}}}\left(a_{\mathrm{T}_{i}} \omega\right)}{N}, \\
& \mu_{E_{1_{i}}}=\sqrt{\frac{\sum_{a_{\mathrm{T}_{i}} \omega}\left[\delta_{E_{1_{i}}}\left(a_{\mathrm{T}_{i}} \omega\right)-\overline{\delta_{E_{1_{i}}}}\right]^{2}}{N}}, \\
& \overline{\delta_{E_{2_{i}}}}=\frac{\sum_{a_{\mathrm{T}_{i}} \omega} \delta_{E_{2_{i}}}\left(a_{\mathrm{T}_{i}} \omega\right)}{N} \\
& \mu_{E_{2_{i}}}=\sqrt{\frac{\sum_{a_{\mathrm{T}_{i}} \omega}\left[\delta_{E_{2_{i}}}\left(a_{\mathrm{T}_{i}} \omega\right)-\overline{\delta_{E_{2_{i}}}}\right]^{2}}{N}},
\end{aligned}
$$

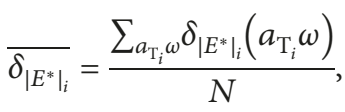

$$
\begin{aligned}
& \mu_{\left|E^{*}\right|_{i}}=\sqrt{\frac{\sum_{a_{\mathrm{T}_{i}} \omega}\left[\delta_{\left|E^{*}\right|_{i}}\left(a_{\mathrm{T}_{i}} \omega\right)-\overline{\delta_{\left|E^{*}\right|_{i}}}\right]^{2}}{N}}, \\
& \overline{\delta_{\varphi_{i}}}=\frac{\sum_{a_{\mathrm{T}_{i}}} \delta_{\varphi_{i}}\left(a_{\mathrm{T}_{i}} \omega\right)}{N}, \\
& \mu_{\varphi_{i}}=\sqrt{\frac{\sum_{a_{\mathrm{T}_{i}} \omega}\left[\delta_{\varphi_{i}}\left(a_{\mathrm{T}_{i}} \omega\right)-\overline{\delta_{\varphi_{i}}}\right]^{2}}{N}} .
\end{aligned}
$$

Equations (38)-(41) were used to calculate average values $\left(\overline{\Delta_{E_{1}}}, \overline{\Delta_{E_{2 i}}}, \overline{\Delta_{\mid E^{*} l_{i}}}\right.$, and $\left.\overline{\Delta_{\varphi_{i}}}\right)$ and standard deviations $\left(M_{E_{1}}, M \mu_{E_{2 i}}, M \mu_{\left|E^{*}\right|_{i}}^{2}\right.$, and $\left.M_{\varphi_{i}}\right)$ of absolute values of relative and absolute errors $\delta_{E_{1}}, \delta_{E_{2}}, \delta_{\left|E^{*}\right|_{i}}$, and $\delta_{\varphi_{i}}$ of each user at the $N$ considered equivalent frequencies $a_{\mathrm{T}_{i}}(N=55)$, plotted in histograms of Figure 13. As shown in Figure 12, error bars are plotted according to standard deviation values.

$$
\begin{aligned}
\overline{\Delta_{E_{1_{i}}}} & =\frac{\sum_{a_{\mathrm{T}_{i}} \omega}\left|\delta_{E_{1_{i}}}\left(a_{\mathrm{T}_{i}} \omega\right)\right|}{N}, \\
M_{E_{1_{i}}} & =\sqrt{\frac{\sum_{a_{\mathrm{T}_{i}} \omega}\left[\left|\delta_{E_{1_{i}}}\left(a_{\mathrm{T}_{i}} \omega\right)\right|-\overline{\Delta_{E_{1_{i}}}}\right]^{2}}{N}} \\
\overline{\Delta_{E_{2_{i}}}} & =\frac{\sum_{a_{\mathrm{T}_{i}} \omega \mid}\left|\delta_{E_{2_{i}}}\left(a_{\mathrm{T}_{i}} \omega\right)\right|}{N}, \\
M_{E_{2_{i}}} & =\sqrt{\frac{\left.\sum_{a_{\mathrm{T}_{i}} \omega} \omega\left|\delta_{E_{2_{i}}}\left(a_{\mathrm{T}_{i}} \omega\right)\right|-\overline{\Delta_{E_{2_{i}}}}\right]^{2}}{N}},
\end{aligned}
$$

$$
\begin{aligned}
\overline{\Delta_{\left|E^{*}\right|_{i}}} & =\frac{\sum_{a_{\mathrm{T}_{i}} \omega}\left|\delta_{\left|E^{*}\right|_{i}}\left(a_{\mathrm{T}_{i}} \omega\right)\right|}{N}, \\
M_{\left|E^{*}\right|_{i}} & =\sqrt{\frac{\sum_{{a_{\mathrm{T}}}_{i} \omega}\left[\left|\delta_{\left|E^{*}\right|_{i}}\left(a_{\mathrm{T}_{i}} \omega\right)\right|-\overline{\Delta_{\left|E^{*}\right|_{i}}}\right]^{2}}{N}}, \\
\overline{\Delta_{\varphi_{i}}} & =\frac{\sum_{a_{\mathrm{T}_{i}} \omega \mid}\left|\delta_{\varphi_{i}}\left(a_{\mathrm{T}_{i}} \omega\right)\right|}{N}, \\
M_{\varphi_{i}} & =\sqrt{\frac{\sum_{a_{\mathrm{T}_{i}} \omega}\left[\left|\delta_{\varphi_{i}}\left(a_{\mathrm{T}_{i}} \omega\right)\right|-\overline{\Delta_{\varphi_{i}}}\right]^{2}}{N} .}
\end{aligned}
$$

Global error parameters $\overline{\delta_{\left|E^{*}\right|_{i}}}$ and $\overline{\Delta_{\left|E^{*}\right|_{i}}}$ (for $\left|E^{*}\right|$ ) are generally lower than $10 \%$ and parameters $\delta_{\varphi_{i}}$ and $\overline{\Delta_{\varphi_{i}}}$ (for $\varphi$ ) are generally lower than $5^{\circ}$ (even considering the corresponding standard deviations), except for the same few users. These estimates show that very satisfactory simulations were obtained by the vast majority of the users. This observation is all the more relevant because the error parameters were calculated by arithmetically averaging all the 55 data points over the whole frequency range available.

Overall error parameters were calculated for the whole calibration panel by averaging errors obtained for the 14 users, according to equations (42)-(49). The obtained parameters $\left(\widehat{\delta_{E_{1}}}, \widehat{\delta_{E_{2}}}, \widehat{\delta_{\left|E^{*}\right|}}\right.$, and $\widehat{\delta_{\varphi}} ; \widehat{\Delta_{E_{1}}}, \widehat{\Delta_{E_{2}}}, \widehat{\Delta_{\left|E^{*}\right|}}$, and $\widehat{\Delta_{\varphi}}$ for absolute values of errors) and corresponding standard deviations $\left(\widehat{\mu_{E_{1}}}, \widehat{\mu_{E_{2}}}, \widehat{\mu_{\mid E^{*}}}\right.$, and $\widehat{\mu_{\varphi}} ; \widehat{M_{E_{1}}}, \widehat{M_{E_{2}}}$, $\widehat{M_{\left|E^{*}\right|}}$, and $\widehat{M}_{\varphi}$ for absolute values of errors) are reported in Table 4.

$$
\begin{aligned}
& \widehat{\delta_{E_{1}}}=\frac{\sum_{i} \sum_{a_{\mathrm{T}_{i}} \omega} \delta_{E_{1_{i}}}\left(a_{\mathrm{T}_{i}} \omega\right)}{14 N}, \\
& \widehat{\mu_{E_{1}}}=\sqrt{\frac{\sum_{i} \sum_{a_{\mathrm{T}_{i}} \omega}\left[\delta_{E_{1_{i}}}\left(a_{\mathrm{T}_{i}} \omega\right)-\widehat{\delta_{E_{1_{i}}}}\right]^{2}}{14 N},} \\
& \widehat{\delta_{E_{2}}}=\frac{\sum_{i} \sum_{a_{\mathrm{T}_{i}} \omega} \delta_{E_{2_{i}}}\left(a_{\mathrm{T}_{i}} \omega\right)}{14 N}, \\
& \widehat{\mu_{E_{2}}}=\sqrt{\frac{\sum_{i} \sum_{a_{\mathrm{T}_{i}} \omega}\left[\delta_{E_{2_{i}}}\left(a_{\mathrm{T}_{i}} \omega\right)-\widehat{\delta_{E_{2_{i}}}}\right]^{2}}{14 N}}, \\
& \widehat{\delta_{\left|E^{*}\right|}}=\frac{\sum_{i} \sum_{a_{\mathrm{T}_{i}} \omega_{\left|E^{*}\right|}} \delta_{\mid E_{i}}\left(a_{\mathrm{T}_{i}} \omega\right)}{14 N}, \\
& \sqrt{\frac{\sum_{i} \sum_{a_{\mathrm{T}_{i}} \omega}\left[\delta_{\left|E^{*}\right|_{i}}\left(a_{\mathrm{T}_{i}} \omega\right)-\widehat{\delta_{\left|E^{*}\right|_{i}}}\right]^{2}}{14 N}}
\end{aligned}
$$




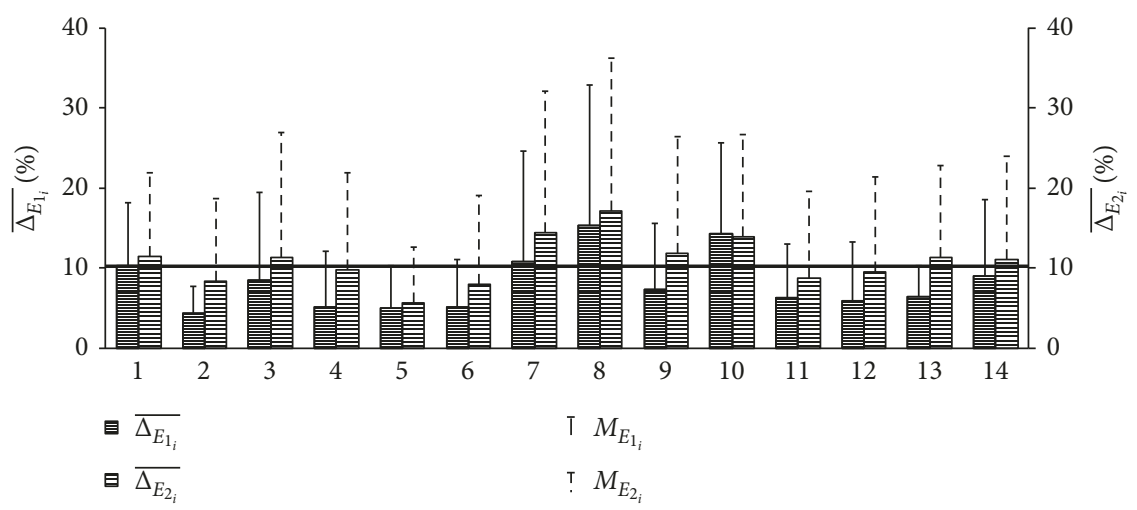

(a)

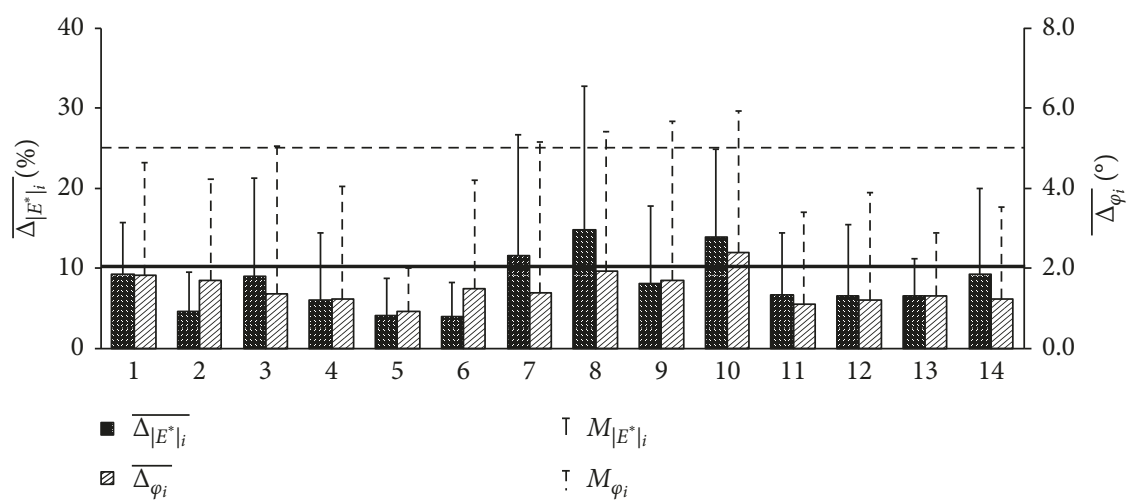

(b)

FIGURE 13: Histograms of global errors of 2S2P1D model fitting of all users for the bituminous mixture (Figure 9), calculated according to equations (38)-(41): (a) relative errors for $E_{1}$ and $E_{2}\left(\overline{\Delta_{E_{1}}}\right.$ and $\overline{\Delta_{E_{2}}}$, respectively); (b) relative error for $\left|E^{*}\right|\left(\overline{\Delta_{\mid E^{*}}}\right)$ and absolute error for $\varphi$ $\left(\overline{\Delta_{\varphi_{i}}}\right)$. Error bars are plotted according to standard deviations $M_{E_{1_{i}}}, M \mu_{E_{2_{i}}}, M \mu_{\left|E^{*}\right|_{i}}$, and $M_{\varphi_{i}}$.

TABLE 4: Global errors of 2S2P1D model fitting for a bituminous mixture, calculated for the whole calibration panel according to equations (42)-(49).

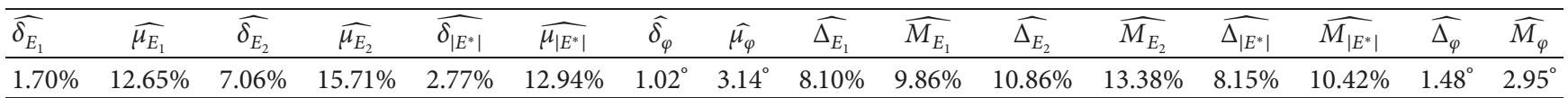

$$
\begin{gathered}
\widehat{\delta_{\varphi}}=\frac{\sum_{i} \sum_{a_{\mathrm{T}_{i}} \omega} \delta_{\varphi_{i}}\left(a_{\mathrm{T}_{i}} \omega\right)}{14 N}, \\
\widehat{\mu_{\varphi}}=\sqrt{\frac{\sum_{i} \sum_{a_{\mathrm{T}_{i}} \omega}\left[\delta_{\varphi_{i}}\left(a_{\mathrm{T}_{i}} \omega\right)-\widehat{\delta_{\varphi_{i}}}\right]^{2}}{14 N}}, \\
\widehat{\Delta_{E_{1}}}=\frac{\sum_{i} \sum_{a_{\mathrm{T}_{i}} \omega}\left|\delta_{E_{1_{i}}}\left(a_{\mathrm{T}_{i}} \omega\right)\right|}{14 N}, \\
\widehat{M_{E_{1}}}=\sqrt{\frac{\sum_{i} \sum_{a_{\mathrm{T}_{i}} \omega}\left[\left|\delta_{E_{1_{i}}}\left(a_{\mathrm{T}_{i}} \omega\right)\right|-\widehat{\Delta_{E_{1_{i}}}}\right]^{2}}{14 N}},
\end{gathered}
$$

$$
\begin{aligned}
\widehat{\Delta_{E_{2}}} & =\frac{\sum_{i} \sum_{a_{\mathrm{T}_{i}} \omega}\left|\delta_{E_{2_{i}}}\left(a_{\mathrm{T}_{i}} \omega\right)\right|}{14 N}, \\
\widehat{M_{E_{2}}} & =\sqrt{\frac{\sum_{i} \sum_{a_{\mathrm{T}_{i}} \omega}\left[\left|\delta_{E_{2_{i}}}\left(a_{\mathrm{T}_{i}} \omega\right)\right|-\widehat{\Delta_{E_{2_{i}}}}\right]^{2}}{14 N},} \\
\widehat{\Delta_{\left|E^{*}\right|}} & =\frac{\sum_{i} \sum_{a_{\mathrm{T}_{i}} \omega}\left|\delta_{\left|E^{*}\right|_{i}}\left(a_{\mathrm{T}_{i}} \omega\right)\right|}{14 N}, \\
\widehat{M_{\left|E^{*}\right|}} & =\sqrt{\frac{\sum_{i} \sum_{a_{\mathrm{T}_{i}} \omega}\left[\left|\delta_{\left|E^{*}\right|}\left(a_{\mathrm{T}_{i}} \omega\right)\right|-\widehat{\Delta_{\mid E^{*} l_{i}}}\right]^{2}}{14 N}},
\end{aligned}
$$




$$
\begin{aligned}
\widehat{\Delta_{\varphi}} & =\frac{\sum_{i} \sum_{a_{\mathrm{T}_{i}} \omega}\left|\delta_{\varphi_{i}}\left(a_{\mathrm{T}_{i}} \omega\right)\right|}{14 N}, \\
\widehat{M}_{\varphi} & =\sqrt{\frac{\sum_{i} \sum_{a_{\mathrm{T}_{i}} \omega}\left[\left|\delta_{\varphi_{i}}\left(a_{\mathrm{T}_{i}} \omega\right)\right|-\widehat{\Delta_{\varphi_{i}}}\right]^{2}}{14 N} .}
\end{aligned}
$$

\section{Conclusions}

Complex modulus test results obtained for a straight-run bitumen and a bituminous mixture (respectively, $G^{*}$ and $E^{*}$ ) were simulated using 2S2P1D model by 14 users with different levels of expertise of the model. All users worked independently and for the same time duration of one hour to fit the model on both sets of data, providing their own values for all the model constants (including WLF constants at the imposed reference temperatures, $10^{\circ} \mathrm{C}$ for the bitumen and $9.5^{\circ} \mathrm{C}$ for the mixture). The following conclusions can be drawn from the analysis of relative and absolute differences between experimental data of the LVE behaviour of both materials and 2S2P1D simulations obtained by all the users:

(i) 2S2P1D simulations of LVE behaviour of both the bitumen and the bituminous mixture obtained by the users of the calibration panel satisfactorily approximate experimental data of complex modulus ( $G^{*}$ for the bitumen and $E^{*}$ for the mixture) over the whole range of frequencies and temperatures. The accuracy of the model to fit experimental data is all the more evident if the great spans of equivalent frequencies (between $10^{-6}$ and $10^{10} \mathrm{~Hz}$ at the reference temperatures of $10^{\circ} \mathrm{C}$ for the bitumen and $9.5^{\circ} \mathrm{C}$ for the mixture) and complex modulus $\left(\left|G^{*}\right|\right.$ of the bitumen comprised between $10^{-2}$ and $10^{3} \mathrm{MPa} ;\left|E^{*}\right|$ of the mixture comprised between 10 and $40000 \mathrm{MPa}$ ) are taken into consideration.

(ii) Very low values of COV were found for glassy moduli $G_{0}(1.62 \%)$ and $E_{0}(0.57 \%)$, for the bitumen and the mixture, respectively. Generally, the variability (expressed by the COV) of constants $E_{00}$ (for the mixture), $\delta, k, h$, and $\log \tau$ (for both bitumen and mixture) is approximately equal or lower than $20 \%$.

(iii) Acceptable errors were generally observed over the whole range of frequencies and temperatures for the simulations obtained for both bitumen and mixture by all the users of the panel, regardless of their familiarity and experience with the model. The three most experienced users of the panel obtained particularly accurate approximations of experimental data, confirming the ability of the model to simulate LVE behaviour of both bitumens and mixtures.

\section{Conflicts of Interest}

The authors declare that they have no conflicts of interest.

\section{Acknowledgments}

The authors express their profound gratitude to all the other participants of the calibration panel: Thomas Attia, Lucas Babadopulos, Jean-Claude Carret, Philippe Gaborit, Pierre Gayte, Minh Duc Nguyen, Alvaro Pedraza, Cong Viet Phan, Simon Pouget, Diego Ramirez Cardona, and Nouffou Tapsoba.

\section{References}

[1] A. R. Tenpe and A. Patel, "Application of genetic expression programming and artificial neural network for prediction of CBR," Road Materials and Pavement Design, pp. 1-18, 2018.

[2] Z. Ding, L. Li, G. Zou, and J. Kong, "Design sensitivity analysis for transient response of non-viscously damped systems based on direct differentiate method," Mechanical Systems and Signal Processing, vol. 121, pp. 322-342, 2019.

[3] Q. Liu, J. Liu, F. Guan, X. Han, L. Cao, and K. Shan, "Identification of the visco-hyperelastic properties of brain white matter based on the combination of inverse method and experiment," Medical \& Biological Engineering \& Computing, vol. 57, no. 5, pp. 1109-1120, 2019.

[4] I. M. Sobol', "Sensitivity estimates for nonlinear mathematical models," MMCE, vol. 1, pp. 407-414, 1993.

[5] I. M. Sobol', "Global sensitivity indices for nonlinear mathematical models and their Monte Carlo estimates," Mathematics and Computers in Simulation, vol. 55, no. 1-3, pp. 271-280, 2001.

[6] J. S. Marshall, "Modeling and sensitivity analysis of particle impact with a wall with integrated damping mechanisms," Powder Technology, vol. 339, pp. 17-24, 2018.

[7] F. Olard and H. Di Benedetto, "General "2S2P1D" model and relation between the linear viscoelastic behaviours of bituminous binders and mixes," Road Materials and Pavement Design, vol. 4, no. 2, pp. 185-224, 2003.

[8] C. Riccardi, A. C. Falchetto, D. Wang, and M. P. Wistuba, "Effect of cooling medium on low-temperature properties of asphalt binder," Road Materials and Pavement Design, vol. 18, no. S4, pp. 234-255, 2017.

[9] N. I. M. Yusoff, D. Mounier, G. Marc-Stéphane, M. Rosli Hainin, G. D. Airey, and H. Di Benedetto, "Modelling the rheological properties of bituminous binders using the 2S2P1D model," Construction and Building Materials, vol. 38, pp. 395-406, 2013.

[10] H. Di Benedetto, B. Delaporte, and C. Sauzéat, "Threedimensional linear behavior of bituminous materials: experiments and modeling," International Journal of Geomechanics, vol. 7, no. 2, pp. 149-157, 2007.

[11] S. Pouget, C. Sauzéat, H. Di Benedetto, and F. Olard, "From the behavior of constituent materials to the calculation and design of orthotropic bridge structures," Road Materials and Pavement Design, vol. 11, no. S1, pp. 111-144, 2010.

\section{Data Availability}

The data used to support the findings of this study are included within the article. 


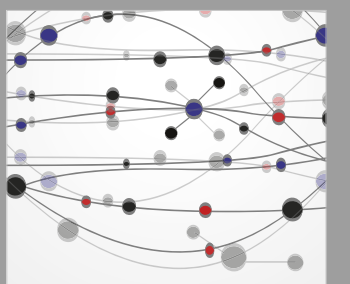

The Scientific World Journal
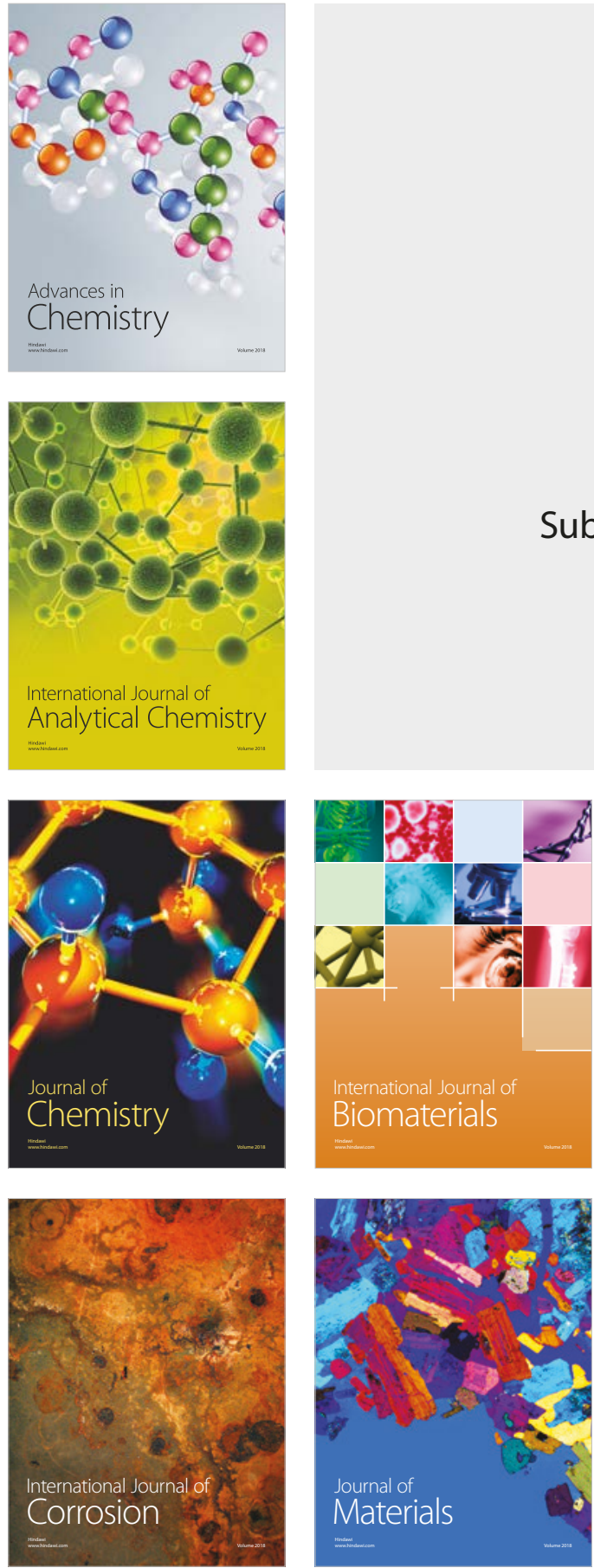

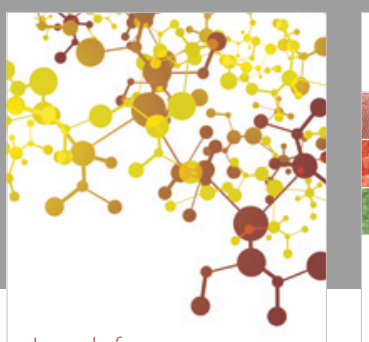

Journal of

Applied Chemistry
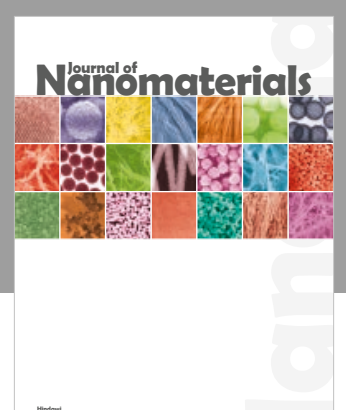

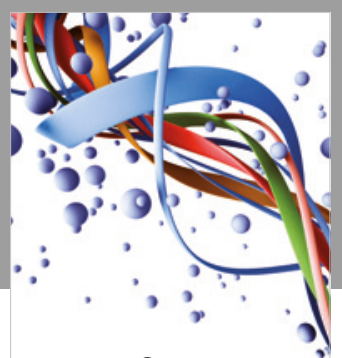

Scientifica

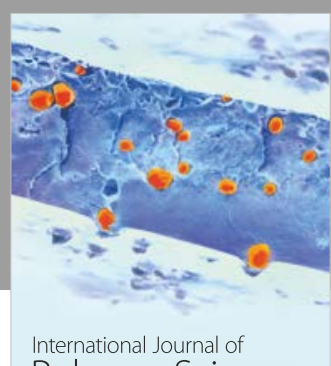

Polymer Science

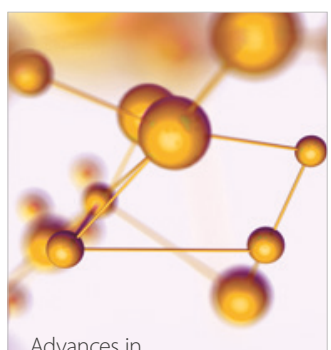

Physical Chemistry
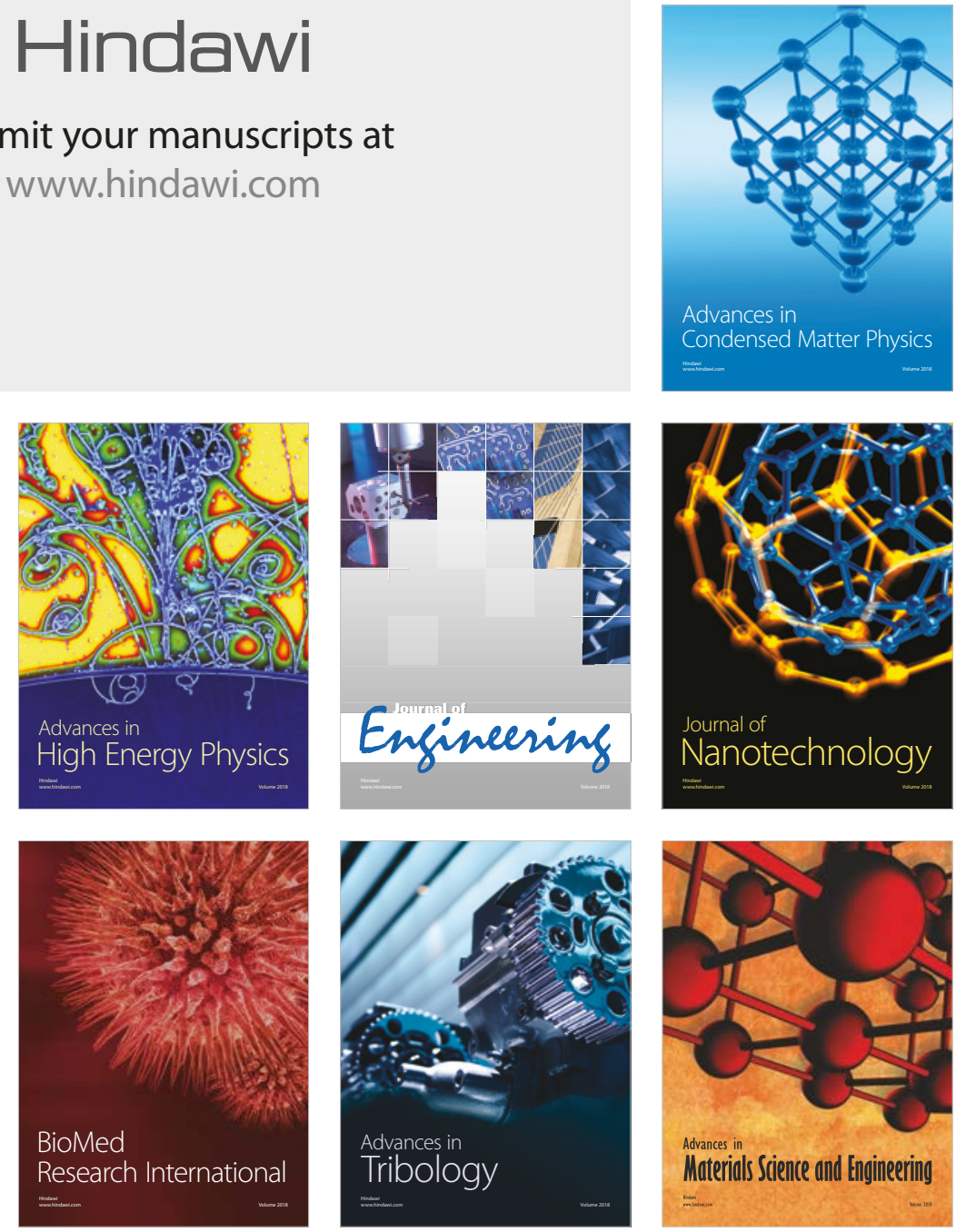